\title{
Unraveling the message: insights into comparative genomics of the naked mole-rat
}

\author{
Kaitlyn N. Lewis ${ }^{1} \cdot$ Ilya Soifer $^{1} \cdot$ Eugene Melamud $^{1} \cdot$ Margaret Roy $^{1}$. \\ R. Scott McIsaac ${ }^{1} \cdot$ Matthew Hibbs $^{2} \cdot$ Rochelle Buffenstein $^{1}$
}

Received: 3 March 2016/Accepted: 9 May 2016/Published online: 30 June 2016

(C) The Author(s) 2016. This article is published with open access at Springerlink.com

\begin{abstract}
Animals have evolved to survive, and even thrive, in different environments. Genetic adaptations may have indirectly created phenotypes that also resulted in a longer lifespan. One example of this phenomenon is the preternaturally long-lived naked mole-rat. This strictly subterranean rodent tolerates hypoxia, hypercapnia, and soil-based toxins. Naked mole-rats also exhibit pronounced resistance to cancer and an attenuated decline of many physiological characteristics that often decline as mammals age. Elucidating mechanisms that give rise to their unique phenotypes will lead to better understanding of subterranean ecophysiology and biology of aging. Comparative genomics could be a useful tool in this regard. Since the publication of a naked mole-rat genome assembly in 2011, analyses of genomic and transcriptomic data have enabled a clearer understanding of mole-rat evolutionary history and suggested molecular pathways (e.g., NRF2-signaling activation and DNA damage repair mechanisms) that may explain the extraordinarily longevity and unique health traits of this species. However, careful scrutiny and reanalysis suggest that some identified features result from incorrect or imprecise annotation and assembly of the naked mole-rat genome: in addition, some of these conclusions (e.g., genes involved in cancer resistance and hairlessness) are rejected when the analysis includes
\end{abstract}

Kaitlyn N. Lewis and Ilya Soifer are the joint first authors.

Rochelle Buffenstein

rbuffen@calicolabs.com

1 Calico Life Sciences LLC, 1170 Veterans Blvd, South San Francisco, CA 94080, USA

2 Computer Science Department, Trinity University, San Antonio, TX 78212, USA additional, more closely related species. We describe how the combination of better study design, improved genomic sequencing techniques, and new bioinformatic and data analytical tools will improve comparative genomics and ultimately bridge the gap between traditional model and nonmodel organisms.

"From elephant to butyric acid bacterium-it is all the same" (Kluyver and Donker 1926). Or, stated another way, "anything found to be true of $E$. coli must also be true of elephants" (Monod 1997). The use of animal models in biomedical research stems from the concept expounded from these famous adages. Indeed, there is a considerable unity in the genomic, molecular, and biochemical mechanisms across bacteria, fungi, worms, flies, mice, elephants, and humans. Most basic biological principles and genetic regulatory mechanisms are thought to have arisen very early in the evolutionary history, as they are similar in prokaryotes, as well as single-cell and multi-cellular eukaryotes. While there is conservation of key molecular pathways among all organisms, during evolution existing components may be rearranged to acquire novel and/or improved functions. For example, at the protein level, subtle differences in fetal versus adult hemoglobin sequences modulate oxygen affinity. Additionally, at the organ level, the development of a vulva in female roundworms provides a mechanism for oviposition and heterosexual reproduction, and this arose from tissue remodeling processes dependent upon numerous cell-cell interactions and intercellular signaling pathways [see (Sternberg 2005)]. Similarly, multiple solutions may have evolved to address specific needs (e.g., formation of different kinds of eyes from existing structures to perceive images and facilitate vision). It is clear that there are many ways 
involving molecular, structural, and/or enzymatic components of achieving a particular function or organ. Such evolutionary tinkering and the concomitant altering or recycling of various components have contributed to integrated adaptations through the process of natural selection (Jacob 1977). It is likely that the tremendous diversity in species lifespan has also arisen as a consequence of evolutionary fiddling when modulation of certain processes may indirectly affect lifespan (Jacob, 1977).

While gymnosperms currently hold the longevity record for living organisms [e.g., the tree tumbo Welwitschia mirabilis (1500 years; Misra et al. 2015) and the bristlecone pine Pinus longaeva (5000 years; Brutovská et al. 2013)]; animal lifespans span an approximately 60,000fold range. Mayflies and gastrotrichs live a mere 3 days and the ocean quahog (hard clam) lives $>500$ years (Carey 2002; Butler et al. 2013). Differences in species maximum lifespan are most apparent when comparing those species living in extreme environments with those living in more favorable, protected, and stable environments; animals living in ephemeral, temporary ponds (e.g., killifish) complete their lifecycle in a matter of days/weeks (Valdesalici and Cellerino 2003), while those living in more stable habitats such as the ocean [e.g., quahog (Butler et al. 2013) and bowhead whale (Craig George and Bockstoce 2008)] can live for centuries, possibly because they are subject to more relaxed evolutionary pressures. Animals living in different niches, particularly those habitats considered harsh, are likely to have evolved distinct mechanisms favoring their survival in that milieu. If not, that particular species would become extinct. Many of these ecophysiological adaptations may also influence species lifespan (Sanchez et al. 2015).

Large differences in species maximum lifespan potential [MLSP] must ultimately be genetically encoded; however, if a specific "lifespan program" existed, one might expect that genetic revertants of such a program could be identified to enable immortality. To date, no such observation has been made. So while it is highly unlikely that age of death is programmed, genetic regulation of the many pathways that contribute to survival of the individual (e.g., resistance to stress, damage eradication, and/or somatic repair), as well as genetic regulation of the metabolic pathways that inflict age-related damage, is likely to be directly involved in organismal longevity (Gems and Partridge 2013).

Observations based on "natural evolutionary experimentation" may elucidate mechanisms explaining how some species are able to live healthier and longer lives than others. Comparative biology may also reveal whether or not a mechanism is unique to a species (i.e., a private mechanism) or ubiquitously shared (i.e., a public mechanism) across evolutionarily distinct clades (Martin 1997;
Partridge and Gems 2002). Comparative genomics is a relatively new field in which the comparison of genome sequences is used to identify candidate genetic variants associated with particular traits of interest (Alfoldi and Lindblad-Toh 2013). While elements of comparative genomics can potentially help identify genetic factors that contribute to extreme longevity, the lack of high-quality genomes, and the large evolutionary distances amongst species pose difficult challenges to overcome in the search for genetic determinants that modulate aging.

\section{Evolution of genes that modulate longevity}

Comparative genomics is a powerful tool that exploits millions of years of evolution to identify the natural mechanisms that may have led not only to prolonged longevity, but also to different phenotypes associated with disparate resistance to cancer and other diseases. These genomic variations, rooted in evolution, are likely to be well conserved and possibly directly pertinent to human health and lifespan. In keeping with the maxim of the Nobel laureate August Krogh, that for every biological question there is an animal model ideally suited to tackle that research focus (Jorgensen 2001), naturally long-lived species—like the naked mole-rat—are prime candidates for identifying mechanisms involved in both delaying the onset, and slowing the rate, of aging.

Aging and longevity research has relied extensively on a battery of commonly used and relatively short-lived eukaryote model organisms, namely yeast, worms, flies, and fish, as well as mice and rats, to explore both genetic and environmental determinants of lifespan. While these short-lived models have each yielded a number of fascinating findings and insights into hypotheses surrounding extended lifespan and healthspan, they may also have constrained this complex, multifactorial field to areas in which they are best suited, most notably short-term intervention studies and genetic manipulations. Studies based upon these organisms revealed that changes in even a single gene (e.g., age-1, phosphatidylinositol 3 kinase) can extend lifespan of Caenorhabditis elegans (Friedman and Johnson 1988). Similar lifespan extension effects are evident in flies and mice when the insulin/IGF, gastric hormone, and the Nrf2/skn-1 detoxification/xenobiotic pathways are genetically manipulated (Kenyon et al. 1993; Brown-Borg et al. 1996; Morris et al. 1996; Clancy et al. 2001; An and Blackwell 2003; Sykiotis and Bohmann 2008; Selman and Withers 2011; Ziv and Hu 2011). Furthermore, various types of dietary restrictions, whether limiting access to calories or amino acids, generally have a conserved effect of enhancing longevity across model systems (McCay et al. 1935; Klass 1977; Weindruch and 
Walford 1982; Jiang 2000; Selman and Withers 2011; McIsaac et al. 2016), although exceptions do exist (Liao et al. 2010). Collectively, these data support the premise that longevity can be modulated, likely through the regulation of nutrient signaling and stress response, which in turn impacts development, growth, reproduction, and survival. Strikingly, monozygotic human twins, as well as genetically identical individuals of these animal models (e.g., C57BL/6 mice), even when housed in the same environment and fed the same diet do not all have the same lifespans, suggesting that stochastic factors and epigenetic drift influence the hazard rate (i.e., the risk of death as it changes over a lifespan) and subsequent mortality (Finch and Kirkwood 2000; Herndon et al. 2002; Fraga et al. 2005)

Collectively, these findings contribute to the many convincing arguments that death and/or aging are neither genetically programmed nor under evolutionary selection pressure (Martin 1997; Partridge and Gems 2002; Kirkwood and Melov 2011). Rather, they are due to co-evolution with other traits. For example, short- and long-lived organisms may exhibit different responses to changes in the environment and thereby indirectly affect survival. Indeed the various nutrient-sensing genes shown to modulate longevity (e.g., insulin/IGF-1, FOXO, mTOR) appear to regulate resource allocation for somatic maintenance and thereby influence survival [reviewed in (Kapahi 2010)].

\section{Mammalian models of aging}

The mouse is the most widely used mammalian model in biomedical research. Raised in cages in protected vivaria, they are not subjected to typical natural selective pressures such as predation or food limitation. In the wild, we contend that rodents are unlikely to die from age-associated disease linked to genomic instability (e.g., cancer) or a disruption in proteostasis (e.g., proteinopathies), as they do in the laboratory. Rather, their death in the wild more commonly results directly from stochastic and random events (e.g., predation, extreme weather conditions leading to starvation, and/or infections) (Collins and Kays 2014). As such, laboratory mice are more like sedentary humans, and are likely to provide many insights into a first world western lifestyle.

The evolutionary theory of aging posits that longevity assurance mechanisms may have evolved in those species that have low extrinsic mortality, such as animals that (a) live underground and are protected from climatic extremes, germs, and predation (e.g., naked mole-rats), (b) can escape hostile habitats (e.g., bats and birds), or (c) have effective body armor (e.g., porcupines and tortoises) (Chen and Maklakov 2012). As such, mice, which experience high extrinsic mortality in the wild and have shorter lifespans than predicted on the basis of body size in captivity, may not necessarily be the best organism with which to search for longevity assurance mechanisms (Buffenstein et al. 2014).

Moreover, as organisms become less fecund with age, the forces governing natural selection decline and the genetic factors that influence somatic maintenance and organismal survival in the face of stochastic damage likely play a greater role in the determination of survival and longevity of the organism (Hamilton 1966). Greater selection pressures that enhance somatic maintenancethereby extending the time taken before accrued damage can induce a significant decline in function and viabilitymay also extend the lifespan of the animal. It is thus highly likely that long-lived species employ different mechanisms to those of short-lived species to defend their soma and are therefore useful animal models to address the evolved mechanisms involved in retarding the aging process and extending longevity, particularly of other long-lived species, like humans. One such animal model of exceptional biogerontological interest is the naked mole-rat (Austad 2009).

\section{Unusual features of the long-lived naked mole-rat}

The naked mole-rat is only one of over 50 subterranean dwelling rodents found throughout the world (Begall et al. 2007; Table 1). This species belongs to the Ctenohystrica supraorder of rodents, made up of the superfamilies Phiomorpha (African mole-rats, rock rats, and porcupines) and Caviomorpha (tuco tucos, degus, and guinea pigs). Recently, it was concluded that naked mole-rats diverged 31 million years ago [mya] prior to the diversification of other African mole-rat species (the Bathyergidae family), and the naked mole-rat has been now placed in a separate family (Heterocephalidae; Fig. 1) (Faulkes et al. 2004; Patterson and Upham 2014). Among mammals, only the Heterocephalidae (the naked mole-rat) and Bathyergidae (African mole-rats, i.e., the long-lived Damaraland molerat [MLSP 20y; Buffenstein pers. com]) include species that are considered truly eusocial (Bennett and Faulkes 2000); in that, similar to the eusocial insects (e.g., wasps, bees, and ants) there is a well-defined social hierarchy in which breeding is restricted to a single female ("the queen") within the colony.

All mole-rat species (collectively the Bathyergidae, Heterocephalidae, and Spalacidae families) occupy underground niches. Although some of these evolutionarily divergent species lead a solitary existence and others live communally, they share many morphological and physiological traits considered adaptive to life below ground 
Table 1 Characteristics of mole-rats (data summarized from Lacey 2000; Begall et al. 2007)

\begin{tabular}{|c|c|c|c|c|c|c|c|}
\hline Species & $\begin{array}{l}\text { Common } \\
\text { name }\end{array}$ & $\begin{array}{l}\text { MLSP } \\
\text { (years) }\end{array}$ & $\begin{array}{l}\text { Body } \\
\text { mass } \\
(\mathrm{g})\end{array}$ & $\begin{array}{l}\text { Haplotype } \\
(2 \mathrm{n})\end{array}$ & Social/Solitary & Reproduction & Ecology \\
\hline $\begin{array}{l}\text { Heterocephalus } \\
\text { glaber }\end{array}$ & $\begin{array}{l}\text { Naked mole- } \\
\text { rat }\end{array}$ & 31 & 40 & 60 & $\begin{array}{l}\text { Eusocial (up to } 295 \\
\text { individuals/colony) }\end{array}$ & $\begin{array}{l}\text { Gestation is } \\
66-74 \text { days. Up } \\
\text { to } 4 \text { litters/year. } \\
1-29 \text { pups/litter }\end{array}$ & $\begin{array}{l}\text { Found in the arid and } \\
\text { semi-arid regions of } \\
\text { north east Africa, in } \\
\text { sandy soils that } \\
\text { become hard during } \\
\text { the dry season, and in } \\
\text { areas with low and } \\
\text { unpredictable rainfall }\end{array}$ \\
\hline $\begin{array}{l}\text { Fukomys } \\
\quad \text { damarensis }\end{array}$ & $\begin{array}{l}\text { Damaraland } \\
\text { mole-rat }\end{array}$ & $16-20.6$ & $60-600$ & 80 & \multirow{14}{*}{$\begin{array}{l}\text { Eusocial/Social } 4 \text { to } \\
\text { over } 45 \\
\text { individuals/colony, } \\
\text { with the eusocial } F \text {. } \\
\text { damarensis having } \\
\text { the largest colonies. } \\
\text { All other species } \\
\text { social }\end{array}$} & \multirow{14}{*}{$\begin{array}{l}\text { Gestation ranges } \\
\text { between } 78 \text { and } \\
111 \text { days. Up to } \\
4 \text { litters/year } F \text {. } \\
\text { damarensis }= \\
78-92 \text { days, } 1-6 \\
\text { pups/litter }\end{array}$} & \multirow{14}{*}{$\begin{array}{l}\text { Found all over sub- } \\
\text { Saharan African } \\
\text { living in a wide range } \\
\text { of soil types and } \\
\text { annual rainfall } \\
\text { patterns }\end{array}$} \\
\hline Fukomys mechowii & $\begin{array}{l}\text { Giant mole- } \\
\text { rat }\end{array}$ & & & 40 & & & \\
\hline Fukomys anselli & $\begin{array}{l}\text { Ansell's } \\
\text { mole-rat }\end{array}$ & & & 69 & & & \\
\hline Fukomys amatus & $\begin{array}{l}\text { Zambian } \\
\text { mole-rat }\end{array}$ & & & 68 & & & \\
\hline Fukomys bocagei & $\begin{array}{l}\text { Angolian } \\
\text { mole-rat }\end{array}$ & & & 58 & & & \\
\hline Fukomys darlingi & $\begin{array}{l}\text { Mashona } \\
\text { mole-rat }\end{array}$ & & & 54 & & & \\
\hline Fukomys ilariae & $\begin{array}{l}\text { Somali } \\
\text { striped } \\
\text { mole-rat }\end{array}$ & & & Unknown & & & \\
\hline Fukomys kafuensis & $\begin{array}{l}\text { Kafue mole- } \\
\text { rat }\end{array}$ & & & $42-58$ & & & \\
\hline $\begin{array}{l}\text { Fukomys } \\
\quad \text { vandewoestijneae }\end{array}$ & $\begin{array}{r}\text { Caroline's } \\
\text { mole-rat }\end{array}$ & & & 44 & & & \\
\hline Fukomys micklemi & $\begin{array}{l}\text { Kataba mole- } \\
\text { rat }\end{array}$ & & & $42-68$ & & & \\
\hline Fukomys whytei & $\begin{array}{r}\text { Malawian } \\
\text { mole-rat }\end{array}$ & & & 46 & & & \\
\hline Fukomys foxi & $\begin{array}{l}\text { Nigerian } \\
\text { mole-rat }\end{array}$ & & & Unknown & & & \\
\hline Fukomys zechi & $\begin{array}{l}\text { Togo(Ghana) } \\
\text { mole-rat }\end{array}$ & & & Unknown & & & \\
\hline $\begin{array}{l}\text { Fukomys } \\
\quad \text { ochraceocinereus }\end{array}$ & $\begin{array}{l}\text { Ochre mole- } \\
\text { rat }\end{array}$ & & & Unknown & & & \\
\hline $\begin{array}{l}\text { Cryptomys } h . \\
\text { hottentotus }^{\mathrm{a}}\end{array}$ & $\begin{array}{l}\text { Common } \\
\text { mole-rat }^{\mathrm{a}}\end{array}$ & 11 & $57-110$ & 54 & $\begin{array}{l}\text { Social, } 8-16 \\
\text { individuals/colony }\end{array}$ & $\begin{array}{l}\text { Gestation is } \\
59-66 \text { days. Up } \\
\text { to } 2 \text { litters/year. } \\
2-4 \text { pups/litter }\end{array}$ & $\begin{array}{l}\text { Found in South Africa } \\
\text { in a wide range of soil } \\
\text { types and annual } \\
\text { rainfall patterns }\end{array}$ \\
\hline $\begin{array}{l}\text { Heliophobius } \\
\text { argenteocinereus }\end{array}$ & $\begin{array}{l}\text { Silvery mole- } \\
\text { rat }\end{array}$ & $>7.5$ & 160 & 62 & Solitary, aggressive & $\begin{array}{l}\text { Gestation is } 87 \\
\text { days. } 2-4 \text { pups/ } \\
\text { litter }\end{array}$ & $\begin{array}{l}\text { Lives in sandy soils of } \\
\text { savannahs and } \\
\text { woodlands with high } \\
\text { annual rainfall }\end{array}$ \\
\hline $\begin{array}{l}\text { Georychus } \\
\text { capensis }\end{array}$ & Cape mole-rat & 11.2 & 180 & 54 & Solitary & $\begin{array}{l}\text { Gestation is } \\
44-48 \text { days. Up } \\
\text { to } 2 \text { litters/year. } \\
4-10 \text { pups/litter }\end{array}$ & $\begin{array}{l}\text { Found in sandy and } \\
\text { clay soils in mesic } \\
\text { habitats with winter } \\
\text { rainfall patterns }\end{array}$ \\
\hline
\end{tabular}


Table 1 continued

\begin{tabular}{|c|c|c|c|c|c|c|c|}
\hline Species & $\begin{array}{l}\text { Common } \\
\text { name }\end{array}$ & $\begin{array}{l}\text { MLSP } \\
\text { (years) }\end{array}$ & $\begin{array}{l}\text { Body } \\
\text { mass } \\
(\mathrm{g})\end{array}$ & $\begin{array}{l}\text { Haplotype } \\
(2 \mathrm{n})\end{array}$ & Social/Solitary & Reproduction & Ecology \\
\hline Bathyergus janetta & $\begin{array}{l}\text { Namaqua } \\
\text { dune mole- } \\
\text { rat }\end{array}$ & $>6$ & $\begin{array}{l}\text { Up to } \\
1000\end{array}$ & 54 & Solitary & \multirow{2}{*}{$\begin{array}{l}\text { Gestation is } 52 \\
\text { days. Up to } 2 \\
\text { litters/year. } 1-7 \\
\text { pups/litter }\end{array}$} & \multirow{2}{*}{$\begin{array}{l}\text { Found along } \\
\text { southwestern African } \\
\text { coastal sand dunes. } B . \\
\text { suillus is found in } \\
\text { areas of high rainfall, } \\
\text { and } B \text {. janetta in areas } \\
\text { with very low rainfall }\end{array}$} \\
\hline Bathyergus suillus & $\begin{array}{c}\text { Cape dune } \\
\text { mole-rat }\end{array}$ & & & 56 & & & \\
\hline Spalax ehrenbergi ${ }^{\mathrm{b}}$ & $\begin{array}{l}\text { Blind mole- } \\
\text { rat }^{\mathrm{b}}\end{array}$ & 20.2 & 120 & $52-60$ & $\begin{array}{l}\text { Solitary, varying } \\
\text { levels of aggression }\end{array}$ & $\begin{array}{l}\text { Gestation is } 34 \\
\text { days. } 1 \text { litter/ } \\
\text { year. } 1-5 \text { pups/ } \\
\text { litter }\end{array}$ & $\begin{array}{l}\text { Dozens of different } \\
\text { biological species live } \\
\text { in different climates } \\
\text { and with distinct } \\
\text { haplotypes distributed } \\
\text { throughout the middle } \\
\text { east }\end{array}$ \\
\hline Myospalax baileyi & Plateau zokor & \multirow[t]{3}{*}{ Unknown } & \multirow{3}{*}{$\begin{array}{l}\text { Up to } \\
720\end{array}$} & \multirow[t]{3}{*}{ Unknown } & \multirow[t]{3}{*}{ Solitary } & \multirow[t]{3}{*}{ Unknown } & \multirow{3}{*}{$\begin{array}{l}\text { Distributed throughout } \\
\text { Asia }\end{array}$} \\
\hline $\begin{array}{l}\text { Myospalax } \\
\text { myospalax }\end{array}$ & $\begin{array}{l}\text { Siberian } \\
\text { zokor }\end{array}$ & & & & & & \\
\hline $\begin{array}{l}\text { Myospalax } \\
\text { psilurus }\end{array}$ & $\begin{array}{l}\text { Transbaikal } \\
\text { zokor }\end{array}$ & & & & & & \\
\hline $\begin{array}{l}\text { Eospalax } \\
\text { fontanierii }\end{array}$ & $\begin{array}{c}\text { Chinese } \\
\text { zokor }\end{array}$ & \multirow[t]{3}{*}{ Unknown } & \multirow[t]{3}{*}{$\begin{array}{l}\text { Up to } \\
600\end{array}$} & \multirow[t]{3}{*}{ Unknown } & \multirow[t]{3}{*}{ Solitary } & \multirow[t]{3}{*}{ Unknown } & \multirow{3}{*}{$\begin{array}{l}\text { Distributed throughout } \\
\text { mountainous regions } \\
\text { of China }\end{array}$} \\
\hline $\begin{array}{l}\text { Eospalax } \\
\quad \text { rothschildi }\end{array}$ & $\begin{array}{l}\text { Rothschild's } \\
\text { zokor }\end{array}$ & & & & & & \\
\hline Eospalax smithii & Smith's zokor & & & & & & \\
\hline $\begin{array}{l}\text { Tachyoryctes } \\
\text { splendens }{ }^{\mathrm{c}}\end{array}$ & $\begin{array}{l}\text { East African } \\
\text { mole-rat }^{\mathrm{c}}\end{array}$ & \multirow[t]{2}{*}{$>3.1$} & \multirow[t]{2}{*}{220} & \multirow[t]{2}{*}{48} & \multirow[t]{2}{*}{ Solitary } & \multirow{2}{*}{$\begin{array}{l}\text { Gestation is } \\
36-41 \text { days. Up } \\
\text { to } 2 \text { litters/year. } \\
1-3 \text { pups/litter }\end{array}$} & \multirow{2}{*}{$\begin{array}{l}\text { Located in east and } \\
\text { central Africa in } \\
\text { multiple habitats }\end{array}$} \\
\hline $\begin{array}{l}\text { Tachyoryctes } \\
\text { macrocephalus }\end{array}$ & $\begin{array}{l}\text { Big-headed } \\
\text { mole-rat }\end{array}$ & & & & & & \\
\hline Rhizomys sinensis & $\begin{array}{l}\text { Chinese } \\
\text { bamboo rat }\end{array}$ & \multirow[t]{4}{*}{$>4$} & \multirow[t]{4}{*}{$\begin{array}{l}\text { Up to } \\
4000\end{array}$} & \multirow[t]{4}{*}{ Unknown } & \multirow[t]{4}{*}{ Solitary } & \multirow[t]{4}{*}{ Unknown } & \multirow{4}{*}{$\begin{array}{l}\text { Distributed throughout } \\
\text { Asia with in a wide } \\
\text { range of habitats }\end{array}$} \\
\hline $\begin{array}{l}\text { Rhizomys } \\
\text { sumatrensis }\end{array}$ & $\begin{array}{l}\text { Sumatra } \\
\text { bamboo rat }\end{array}$ & & & & & & \\
\hline $\begin{array}{l}\text { Rhizomys } \\
\text { pruinosus }\end{array}$ & $\begin{array}{l}\text { Hoary } \\
\text { bamboo rat }\end{array}$ & & & & & & \\
\hline Cannomys badius & $\begin{array}{l}\text { Lesser } \\
\text { bamboo rat }\end{array}$ & & & & & & \\
\hline
\end{tabular}

African mole-rats from the Bathyergid and Heterocephalid families are generally lumped together. They together with blind mole-rats and zokors from Spalacidae are all subterranean dwelling rodents. Social structure varies considerably within these families, with some species eusocial, social, or solitary. Naked, Damaraland, and blind mole-rats are the most heavily researched with regard to their genome sequencing, and other physiological and biochemical characteristics that may contribute to their long lifespans, and prolonged healthspans

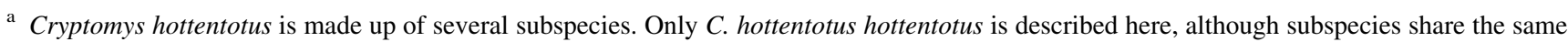
haplotype and are of a similar body size

b The blind mole-rats (referenced as the superspecies Spalax ehrenbergi here) also include a number of other Spalax species and subspecies

c Tachyoryctes splendens includes several subspecies

(Tables 1, 2; Bennett and Faulkes 2000; Begall et al. 2007). All mole-rats are herbivores, with most species restricting feeding to plant components found solely below ground, namely bulbs and tubers (Bennett and Faulkes 2000). Moreover, all appear to have lower resting metabolic rates than their above-ground-dwelling counterparts and all appear to be extremely tolerant of hypoxia. All mole-rats studied to date are considered long-lived for their body size, living at least twice as long as predicted allometrically. This phenomenon is most pronounced in the naked mole-rat, which has a longevity quotient (ratio of the observed maximal lifespan to that predicted by body mass) 
Fig. 1 Phylogenetic relationships of rodent species: the Bathyergidae,

Heterocephalidae, and Spalacidae families are in two different suborders of Rodentia. Genome data are often compared between naked molerats and mice; however, mice are more closely related to blind mole-rats (Spalax), which are in the Muroidea superfamily.

Naked mole-rats are more closely related to guinea pigs (Ctenophiomorpha), both species diverged $\sim 39.5$ million years ago (mya). Naked molerats and mice diverged from their common ancestor $\sim 73.1$ mya (and blind molerats from mice $\sim 47.4$ mya). Additionally, mice appear to be evolving faster than either of the mole-rat species, which could account for many of the differences observed between these unique organisms

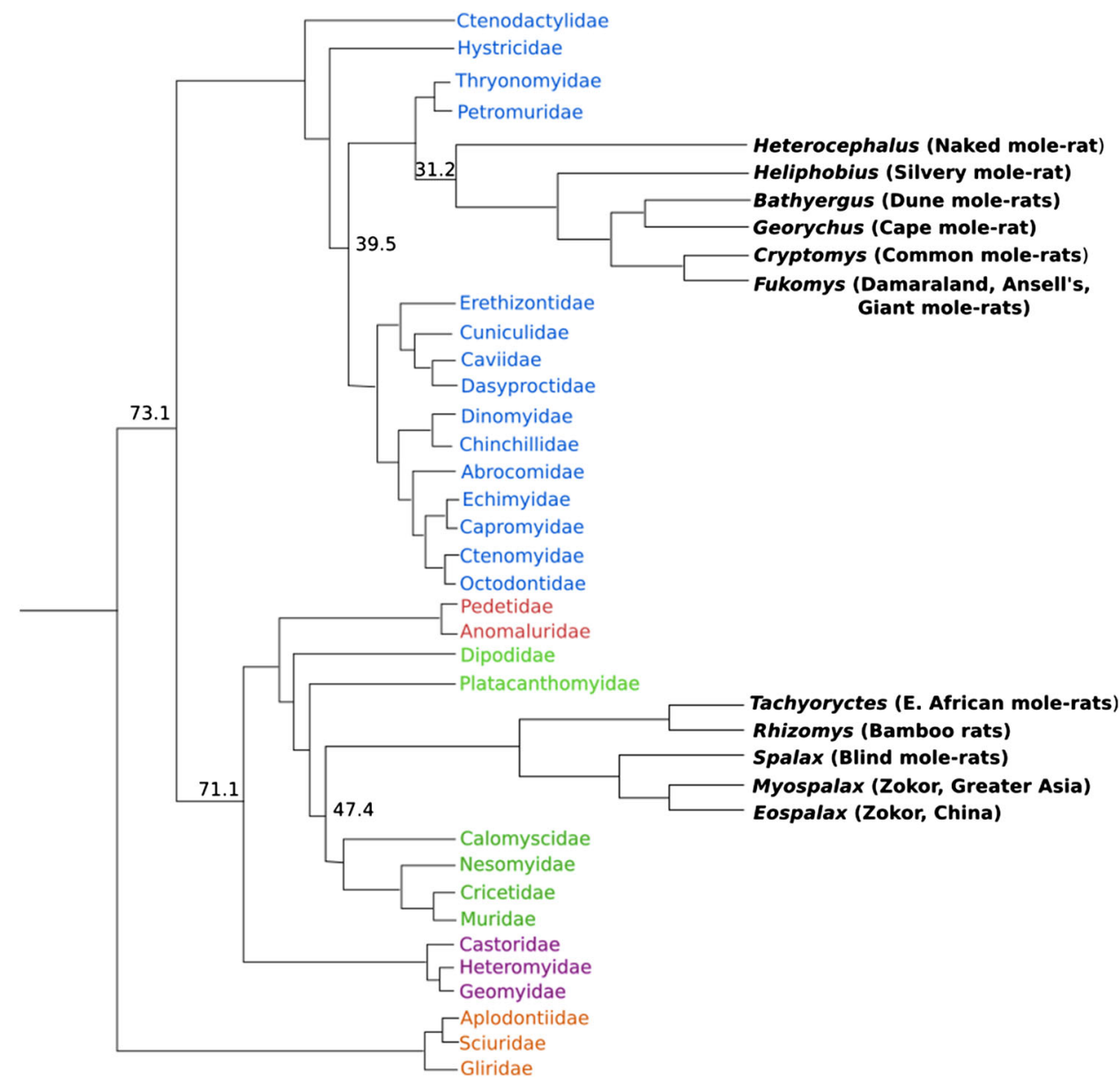

of $>4$, similar to that observed in humans, another very long-living species (Buffenstein 2005).

The naked mole-rat is endemic to the arid and semi-arid regions of north east Africa (Sherman et al. 1991), living in large eusocial family groups in an extensive maze of sealed burrows ranging from 1 to 8 feet below the ground (Jarvis 1981). Having resided in this inhospitable underground milieu in sub-Saharan Africa since the early Miocene ( 23 mya), naked mole-rats are extremely tolerant to a variety of conditions most other species cannot survive, including low partial pressures of oxygen and high amounts of carbon dioxide (Larson and Park 2009; Blass 2014). Naked mole-rats appear to be resistant to the highly poisonous allelochemicals (e.g., cyanide/glycosides) found in the plant storage organs they consume. They are also resistant to a wide variety of toxins, including heavy metals, DNA damaging agents, and chemotherapeutics (Salmon et al. 2008; Lewis et al. 2012), as well as to the toxic effects associated with the nitrogenous wastes (ammonia and methane) in their communal latrines (LaVinka and Park 2012). Collectively, these findings indicate a role for enhanced xenobiotic metabolism mechanisms in the long-lived naked mole-rat and other phylogenetically distant mole-rat species. The evolution of defenses against extrinsic mortality factors likely leads to protection against intrinsic factors linked to metabolic toxic moieties as well.

In vivaria, the naked mole-rat has a maximum captive lifespan that exceeds 30 years (Edrey et al. 2011a). For the better part of these three decades, naked mole-rats exhibit an extended healthspan and compression of the period of morbidity; they experience very little change in a number of physiological and biochemical characteristics that are typically associated with aging, including a sustained lean mass and well-maintained bone composition (O'Connor et al. 2002; Pinto et al. 2010), cardiac function (Grimes et al. 2012, 2014), basal metabolic rate (O'Connor et al. 2002), and proteome maintenance (Perez et al. 2009; Rodriguez et al. 2011). In addition to these distinctive features of slowed and attenuated aging, naked mole-rats are incredibly resistant to spontaneous neoplasia (Seluanov et al. 2009; Liang et al. 2010; Edrey et al. 2011a); over the last four decades of captive housing, reports of cancer are exceedingly rare. We have observed only one occurrence of naturally occurring cancer (a lymphoma in a 21-year-old female) in over 2000 necropsies. Two zoos recently reported rare instances of cancer in their long-maintained 
Table 2 A summary of common phenotypic characteristics of subterranean rodents

\begin{tabular}{|c|c|c|c|c|}
\hline Phenotype & Naked mole-rat & Damaraland mole-rat & Blind mole-rat & Mouse \\
\hline Eye size (diameter mm) & $\sim 0.75$ & $\sim 1.5$ & $\begin{array}{l}\text { Completely } \\
\text { degenerate }\end{array}$ & $\sim 3$ \\
\hline Retina & $\begin{array}{l}\text { Regressive and } \\
\text { disorganized }\end{array}$ & Irregularly structured & $\begin{array}{r}\text { Vestigial and } \\
\text { reorganized }\end{array}$ & Strict organization \\
\hline Detection of light images & Yes/no & Yes/no & Yes/no & $\begin{array}{l}\text { Yes/can detect detailed } \\
\text { image }\end{array}$ \\
\hline External ear pinnae & No & No & No & Yes \\
\hline $\begin{array}{l}\text { Highly developed tactile vibrissae all } \\
\text { over body }\end{array}$ & Yes & Yes & Yes & On face only \\
\hline Internal testes in males & Yes & Yes & Yes & No \\
\hline Mode of digging & Chisel tooth & Chisel tooth & $\begin{array}{l}\text { Head-lift and chisel } \\
\text { tooth }\end{array}$ & Feet \\
\hline Strict Herbivores & Yes & Yes & Yes & No \\
\hline Body temperature $\left({ }^{\circ} \mathrm{C}\right)$ & 33 & 35 & 35 & 37 \\
\hline $\begin{array}{l}\text { Mass specific metabolic rate (\% } \\
\text { predicted by mass) }\end{array}$ & 50 & 57 & 84 & 130 \\
\hline $\begin{array}{l}\text { Thermal conductance }(\% \text { predicted by } \\
\text { mass) }\end{array}$ & 254 & 134 & 150 & 100 \\
\hline Precision of thermoregulation & $\begin{array}{l}\text { Predominantly } \\
\text { thermally labile }\end{array}$ & $\begin{array}{l}\text { Predominantly } \\
\text { homeothermic }\end{array}$ & $\begin{array}{l}\text { Predominantly } \\
\text { homeothermic }\end{array}$ & Strictly homeothermic \\
\hline $\begin{array}{l}\text { NST capacity (fold increase relative to } \\
\text { BMR) }\end{array}$ & 4 & 2 & 3 & 2 \\
\hline Heart rate (beats per min) & $200-370$ & $150-300$ & $110-200$ & $350-850$ \\
\hline Heart rate $(\%$ expected $)$ & 45 & 45 & 43 & $>120$ \\
\hline Hematocrit (\%) & 46 & 48 & 45 & 38 \\
\hline Hemoglobin (g/dL) & 14 & 14 & 15 & 12 \\
\hline Tolerance of hypoxia/hypercapnia & High & High & High & Low \\
\hline
\end{tabular}

Subterranean rodents share a number of features considered adaptations for life underground. The three mole-rat species (the naked, Damaraland, and blind mole-rat) highlighted here represent the Heterocephalidae, Bathyergidae, and Spalacidae families. All are morphologically streamlined (lack of ear pinnae and cryptorchidism), visually impaired with greater reliance on the somatosensory system. Linked to life in a sealed burrow system where gas exchange is restricted to diffusion through soil, all show reduced metabolic rates, heart rates, and oxygen consumption with concomitant changes in blood oxygen carrying capacity. Not surprisingly, mole-rats are resistant to hypoxia and hypercapnia; neither convective cooling nor evaporative water loss is particularly effective in humid sealed burrows, rather loss of metabolic heat is primarily facilitated by high rates of thermal conductance. Low metabolic rates coupled with high rates of thermal conductance give rise to lower resting body temperatures and less strict regulation of body temperature than observed in species that live above ground. Data obtained from (Bennett and Faulkes 2000; Lacey 2000; Cernuda-Cernuda et al. 2002; Begall et al. 2007)

naked mole-rats (Delaney et al. 2016). Naked mole-rats show pronounced resistance to experimentally induced tumorigenesis (Liang et al. 2010) as well. In sharp contrast, cancer is often observed in C57BL/6 mice; even when cancer is not the direct cause of death, the majority of mice die with some signs of neoplastic lesions (Ikeno et al. 2009). Pronounced cancer vulnerability is thought to contribute significantly to the short lifespan of most laboratory mouse strains, which is approximately half of that predicted on the basis of body size (Hulbert et al. 2007).

Whereas in eusocial insects such as bees, the queens have maximum lifespans that are 2-10 fold longer than worker insects (Howell and Usinger 1933; Bozina 1961; Ribbands 1964; Wilson 1971; Seeley 1978; Hölldobler and Wilson 1990), the mole-rat breeding female (i.e., the colony's queen) exhibits a lifespan similar to that of the subordinates in captive colonies (Buffenstein 2008). Although there are very few data on longevity of mole-rats in their native habitat, it has been reported that in the wild, with an army of subordinates to provide food and protection for the queens, the dominant breeders are found in the same burrow system for $\sim 17$ years, 4-fold longer than wild-living subordinates that may be preyed upon when foraging or may leave their natal colony during dispersal events (Begall et al. 2007).

Strikingly, the queen shows no decline in fertility with age and continues to produce offspring throughout her long life (Edrey et al. 2011b), with the ability to produce $>1000$ offspring during her "reign" (Buffenstein 2005). With only one breeding female and 1-4 breeding males in sealed 
underground habitats, these colonies not only remain relatively isolated from other populations of naked mole-rats, but also exhibit considerable inbreeding (Sherman et al. 1991). Indeed, DNA fingerprinting reveals that naked mole-rats have the highest coefficient of inbreeding (0.45) for any natural populations of mammals on record (Reeve et al. 1990). A small fraction $(<1 \%)$ of the mole-rat population belongs to the "dispersomorph" caste (animals that occasionally abandon their colony in search of a new colony) and are thought to play a critical role in increasing genetic heterogeneity (O'Riain et al. 1996; Clarke and Faulkes 1997; Faulkes et al. 1997).

\section{Genomics and transcriptomics of the naked mole-rat}

Three studies have generated a significant amount of genomic (Kim et al. 2011; Keane et al. 2014,) and transcriptomic (Yu et al. 2011) data for the naked mole-rat. A handful of additional studies used these data to delve into the more unusual features of naked mole-rats (Kim et al. 2011; Fang et al. 2014; Davies et al. 2015). Here, we will discuss how methods of analysis, study design, and data quality can have a profound impact on effectively revealing mechanisms that might explain unique features of the naked mole-rat. We review these data and report on key findings as well as highlight areas where additional research and genomic analyses are needed.

\section{Genome assembly of the naked mole-rat}

Two groups have independently published (Kim et al. 2011; Keane et al. 2015) draft assemblies of the naked mole-rat genome (Table 3). Both assemblies used shotgun whole-genome sequencing using high coverage Illumina data with a range of insert sizes. This approach is commonly used and has been applied to many species (Zerbino and Birney 2008; Li et al. 2010; Gnerre et al. 2011; Luo et al. 2012). The drawback of this approach, however, is that the assemblies are relatively fragmented and contain a high percentage $(15 \%)$ of unfilled gaps, hindering analyses of gene regulation and expression. Early short-read Illumina assemblies were shown to contain a significant number of misassemblies and may collapse homologous genes and/or pseudogenes (Zimin et al. 2012). With improvement of sequencing platforms and assemblies (e.g., long-read technologies for whole transcript sequencing (Sharon et al. 2013; Tilgner et al. 2014), as well as the ongoing assembly of many more genomes, the quality of data will continue to improve.

Genomes of comparable species like mouse, rat, and guinea pig (Table 3), on the other hand, have been assembled by several research groups using multiple types of sequencing data (e.g., Illumina shotgun sequencing, Sanger sequencing, bacterial artificial chromosomes, etc.). Because of the inclusion of more types of data, these assemblies are significantly less fragmented and more complete than those of the naked mole-rat. In addition, these assemblies are constantly being updated using new technologies (Lander et al. 2001; Venter et al. 2001; Cheung et al. 2003; Consortium 2004; She et al. 2004; Chaisson et al. 2015). Comparing genomes with different levels of completeness presents a fundamental challenge, limiting both the data interpretations and the conclusions drawn. For example, since better resolution of repetitive elements is expected when using longer reads, the observation of a lower abundance of repetitive elements in the naked mole-rat genome (25 vs. $\sim 35 \%$ in other murid genomes) could be an artifact of the limitations imposed by the different sequencing and assembly technologies used. Thus, researchers should exercise caution when directly comparing genomes of the naked mole-rat to other species for some of the differences observed may be due to technical artifacts rather than evolutionary changes.
Table 3 Comparison of assembly statistics of commonly compared genomes of naked mole-rat, guinea pig, mouse, and human. Data from http:// www.ncbi.nlm.nih.gov/genome/

\begin{tabular}{lllllll}
\hline & \multicolumn{2}{l}{ Naked mole-rat } & & Guinea pig & Mouse & Human \\
\hline Genome & hetGla1 & hetGla2 & Cell Rep & cavPor3 & GRCm38.p4 & GRCh38.ph \\
Assembly size $(\mathrm{Gb})$ & 2.66 & 2.62 & 2.75 & 2.72 & 2.8 & 3.23 \\
Sequencing coverage & $92 \mathrm{x}$ & $90 \mathrm{x}$ & $92 \mathrm{x}$ & $6.8 \mathrm{x}$ & N/A & N/A \\
\# Contigs & 273,990 & 114,653 & N/A & 61,604 & 796 & 1460 \\
Contig N50 (Kb) & 19.3 & 47.8 & 19.3 & 80.6 & 32,273 & 56,413 \\
\# Scaffolds & 39,266 & 4229 & N/A & 3144 & 293 & 801 \\
Scaffold N50 (Mb) & 1585 & 20,533 & 21,307 & 27,942 & 52,589 & 59,364 \\
Unfilled gaps $(\mathrm{Mb})$ & 214 & 303 & N/A & 60 & 79 & 161
\end{tabular}

Note that the naked mole-rat genome assemblies are less contiguous (lower contig N50) and more gapped (higher gap percentage) 


\section{Estimates of gene content}

Approximately, 22,000 genes were identified in the original sequencing (hetGla1) of the naked mole-rat genome (Kim et al. 2011; Bens et al. 2016). This number is similar to that reported in other mammalian genomes. Analysis of gene homology revealed that $\sim 17,000$ naked mole-rat genes have a direct ortholog in either human, mouse, or rat. Moreover, when comparing annotation data (Kim et al. 2011), the naked mole-rat genome appears to exhibit $93 \%$ synteny to that of the human genome, with strikingly less synteny to that of other rodents $(83 \%$ to mouse and $80 \%$ to rat). These differences most likely reflect structural rearrangements when compared to the murid common ancestor. Syntenic comparisons to mammals identified 750 gained genes and 320 lost genes in the naked mole-rat (Kim et al. 2011). Further analysis of these data found 66 additional genes present in naked mole-rat that are absent in 11 other mammals. Since these genes have no known homologs, their function is currently unknown.

The second sequencing and gene annotation (hetGla2) effort (Keane et al. 2014) identified $\sim 42,000$ coding sequences, of which $\sim 13,000$ had a best reciprocal BLAST hit to guinea pig, mouse, or human. Several thousand other coding sequences exhibited high-quality one-way alignments.

Notably, current annotations of the naked mole-rat genome were generated bioinformatically using sequence homology to well-curated genomes (e.g., mouse and human). Yet, approximately $50 \%$ of the RNAseq reads from the naked mole-rat align to the unannotated parts of its genome [Fig. 2; data from Kim et al. (2011)], suggesting that a significant fraction of the transcriptome is escaping gene annotation. This limits transcriptome comparisons only to the recovered orthologs, preventing the identification of novel naked mole-rat genes.

As a potential step forward, a transcriptome assembly based framework (FRAMA) was created that annotated genes from high coverage RNAseq data collected in multiple tissues (Bens et al. 2016), and this seems to be a promising direction in making subsequent analyses more reliable. Using human gene annotations from the highly curated human genome as a point of reference, FRAMA identified $\sim 17,000$ corresponding naked mole-rat genes, indicating that roughly $88 \%$ of human genes have a naked mole-rat ortholog. This suggests that despite a $\sim 90$ mya of divergence, such an approach could perform well for ortholog inference (Bens et al. 2016).

Nevertheless, currently, the best genome annotation algorithms can create incorrect annotations of a genomic sequence even in well-studied genomes, such as humans and mice; this is obviously exacerbated in less well-studied, more exotic species. For instance, miscalled exons in the annotation can cause frameshifts, leading to erroneously truncated genes (Zhang et al. 2012). Such may be

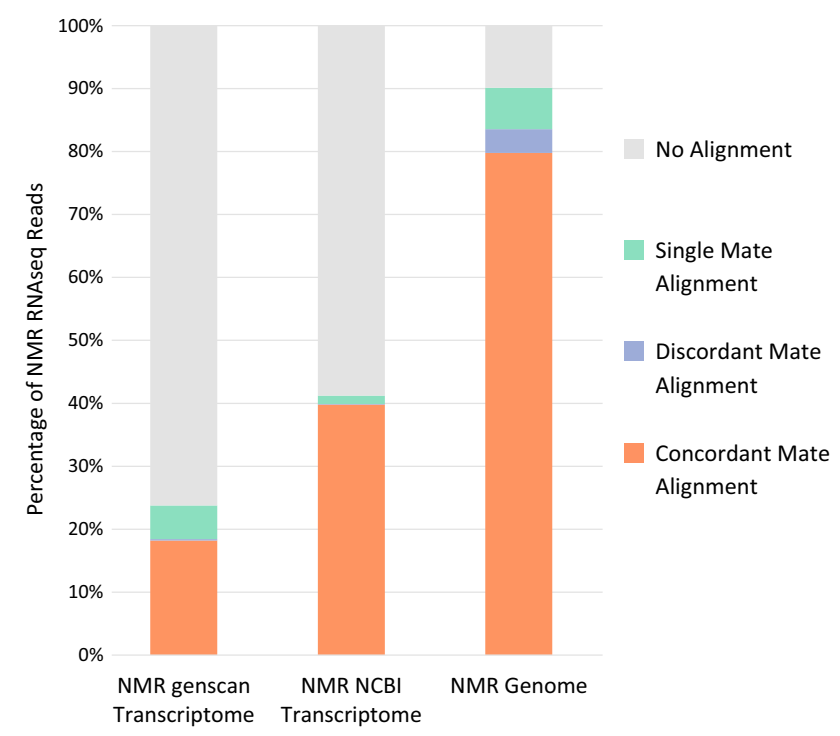

Fig. 2 Alignment rates of naked mole-rat RNA-sequence data to its transcriptomes and genome. Paired-end RNAseq data measured from a mixed pool of 7 naked mole-rat tissues (Kim et al. 2011; SRA: SRS213856) were aligned using Bowtie2 (Ben Langmead and Salzberg 2012) to the naked mole-rat transcriptome derived from genscan annotations (Burge and Karlin 1998), naked mole-rat transcriptome derived from NCBI annotations (Keane et al. 2014), and the entire naked mole-rat genome (hetGla_female_1; Keane et al. 2014). Recent NCBI annotations produce the highest fraction of transcriptome alignments; however, $\sim 40-50 \%$ of RNAseq reads align to the genome, but not the annotated transcriptome. Similar distributions of alignment rates were observed with other alignment methods (not shown)

the case with UCP1 in the cetaceans. It was previously reported that whales (Minke, fin, bowhead, and sperm) all had a premature stop codon in the C-terminal region when compared to terrestrial mammals (Keane et al. 2015). As with the naked mole-rat, changes in UCP1 in these cetaceans potentially contribute to altered mass-specific metabolic rates and thermogenic function, and this change can be inferred to be a "longevity assurance mechanism" that contributes to increased lifespan of these organisms (Keane et al. 2015). However, the most recent data available on NCBI for multiple cetaceans, including dolphins and whales, as well as naked mole-rats, cows, humans, and mice, show that all of these, with the exception of the bowhead whale, have full lengths coding sequences for the UCP1 protein (Fig. 3a). However, this truncated amino acid sequence may result from the loss of one nucleotide in the bowhead whale UCP1 sequence (Fig. 3b). The stopcodon in the genomic sequence may however be a sequencing error. For example, if a " $\mathrm{T}$ " was missed in the Illumina data but hypothetically reinserted bioinformatically, the correct translation for a full length UCP1 gene can occur (Fig. 3c). The type of DNA polymerase employed in the 'sequencing by synthesis' technique (e.g., Illumina) is known to introduce this type of error in 


\section{(A) UCP1 Alignment}

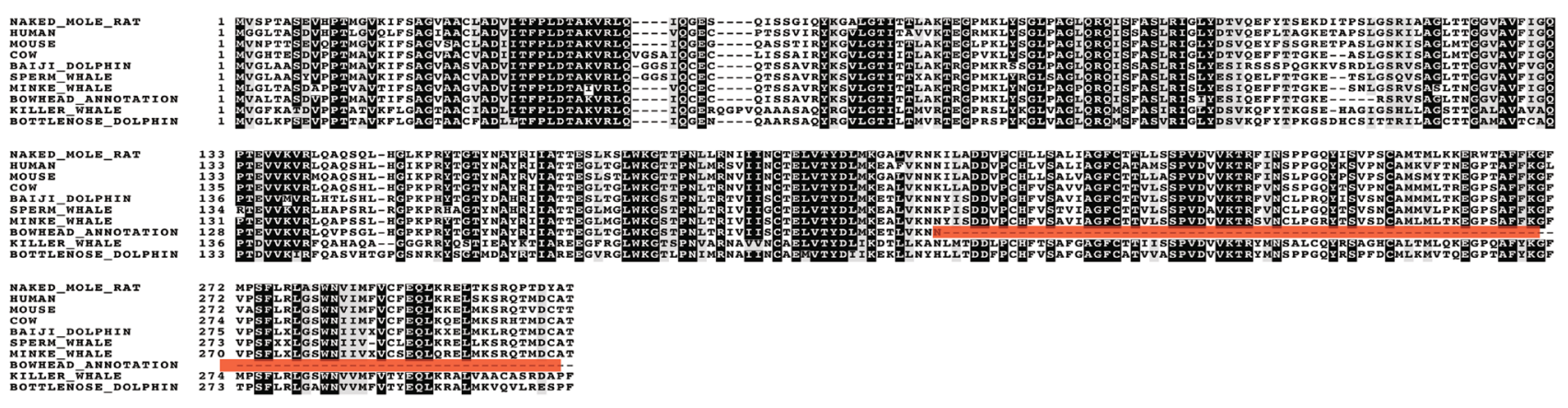

\section{(B) Current Bowhead UCP1 Coding Sequence}

CTAATGAAGGAGACCCTTGTGAAAAACAATTAACAGATGATGTGCCCTGTCACTTTG

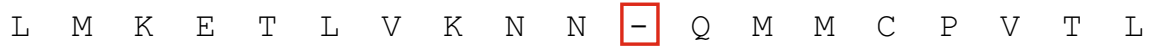

(C) Hypothetical Location of Indel

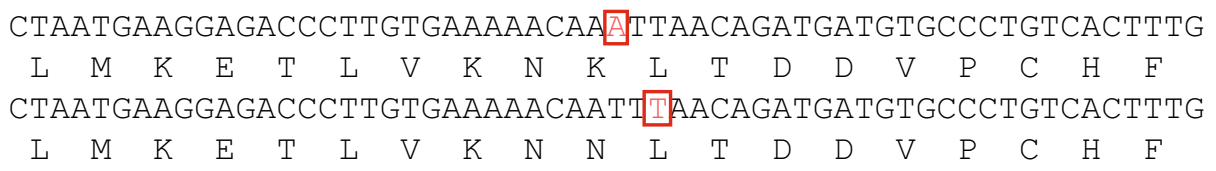

Fig. 3 UCP1 alignment in selected cetaceans, and nonaquatic dwelling mammals. a Alignment of the UCP1 protein. b Bowhead whale UCP1 mRNA revealing a stop codon. c Potential location of

homopolymeric regions (Schirmer et al. 2016). More work is needed to determine if this is indeed an error or a real species difference. As shown in Fig. 3, this gene is well conserved among all the mammals examined beyond the region of the putative stop codon, suggesting that this is not a pseudogene. The presence of the stop codon must be confirmed by additional orthologous genomic methods with different error profiles. This is a cautionary tale and illustrates the necessity of both improved manual curation and whole-genome sequences.

\section{Rapidly and slowly evolving genes}

Interspecies differences in mutation rates are generally thought to indicate different evolutionary pressures, while loss of function and frame-shift mutations are indicative of the loss of selection pressure on the genome to maintain functional protein forms. Sequences with greater accumulation of nonsynonymous differences $\left(K_{\mathrm{a}}\right)$ relative to synonymous differences $\left(K_{\mathrm{s}}\right)$ may highlight key pathways that are under positive selection pressure (Wagner 2002). Thus, $K_{\mathrm{a}} / K_{\mathrm{s}}$ is a convenient marker of selective pressure. Homologous genes with a $K_{\mathrm{a}} / K_{\mathrm{s}}$ ratio greater than 1 are considered to be under positive selection pressure.

Previous studies analyzing orthologous genes of terrestrial and subterranean species revealed that the nucleotide the InDel reveals that a single-nucleotide change could correct the sequence to match that of other mammals

substitution rate of coding sequences was markedly lower in those species that lived below ground (Du et al. 2015; Shao et al. 2015). In general, the rates of both synonymous and nonsynonymous differences have slowed down in the naked mole-rat relative to both the mouse and guinea pig (Du et al. 2015). This apparent decrease in evolutionary rates of change may be associated with life in a stable and protected environment and may be due to a longer generation time. In addition, the naked mole-rat's $\mathrm{Ka} / \mathrm{Ks}$ ratio is higher than that of the mouse and can be attributed to the lack of purifying selection due to a smaller population size (Kim et al. 2011). Intriguingly, the naked mole-rat genes showed greater similarity with humans than with mice (Fig. 4). Note, however, despite a high level of synteny overall, only $\sim 60 \%$ of the annotated naked mole-rat genes have a good one-to-one ortholog to both human and mouse (Keane et al. 2014), suggesting that this comparison is somewhat biased (Fig. 4).

We performed full Smith-Waterman alignment (Smith and Waterman 1981; Zhao et al. 2013) of the naked molerat transcriptome (derived from genscan annotations) to those of the mouse [mm10 UCSC annotations] and the human [hg19 UCSC annotations]. This allows for a more forgiving alignment and is generally considered the gold standard. Despite the limitations of these analyses, the naked mole-rat transcriptome showed double the alignment 
Fig. 4 Divergence between naked mole-rat, mouse, and human protein coding sequence. Outliers from the diagonal represent more than expected accumulation of amino acid changes. Naked mole-rat proteins that show greater similarity to those of humans than to those of mice (as indicated by an increase in $\mathrm{Ka} /$ Ks ratio relative to mouse) are colored in orange and lie above the line of identity

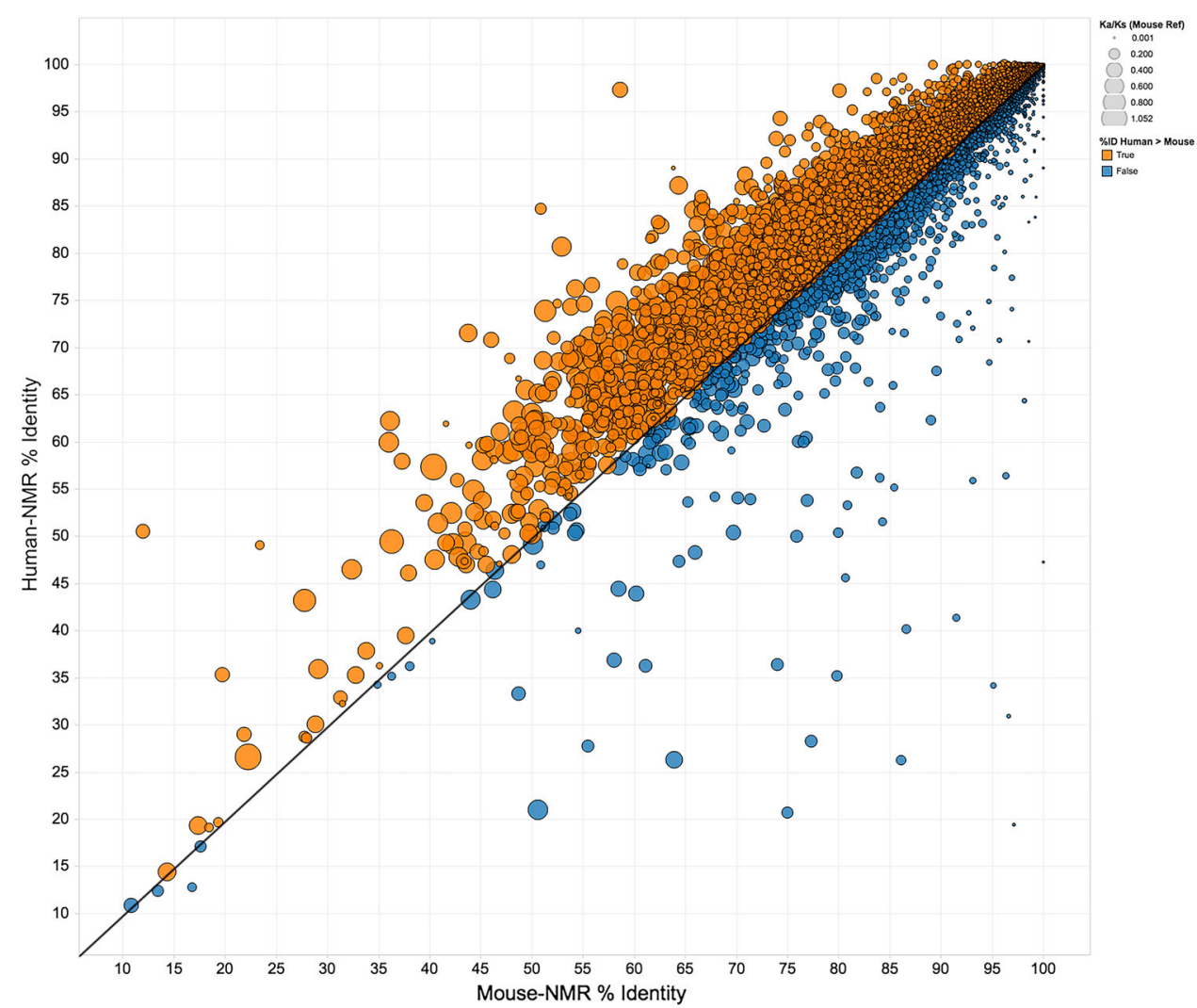

rates and greater parallels with the human transcriptome than that of mouse.

The first study on the naked mole-rat transcriptome was completed prior to the publication of the genome and described only the genes that were upregulated in the naked mole-rat when compared to the C57BL/6 mouse for genes that are expressed at a lower level may simply reflect poor homology with the mouse genome (Yu et al. 2011). Surprising similarities are evident among the transcriptomes of subterranean rodents Spalax galili, Heterocephalus glaber, and Fukomys damarensis (Bennett and Faulkes 2000; Begall et al. 2007; Davies et al. 2015). Several hundred genes are under positive selection in all three of these phylogenetically distinct subterranean rodent species, many of which are likely to reflect shared adaptations to a subterranean lifestyle (i.e., life under hypoxic conditions, resistance to cytotoxins, and cancer).

On the other hand, multiple pathways associated with proteostasis, genomic stability, and cell cycling are more similar between the naked mole-rat, other nonmuroid rodents (including above-ground dwelling rodents, i.e., guinea pigs, chinchillas, squirrels, and jerboas) and humans than among laboratory mice and rats and these species. These pathways likely underwent accelerated evolutionary change in both rats and mice and much slower divergence in the nonmuroid rodents and humans (Vinogradov 2015). This divergence of the Muridae (rats and mice) from the ancestral lineages is thought to reflect a relaxation in purifying selection of these pathways essential for both genomic and proteomic stability (Vinogradov 2015). This may explain the greater propensity for cancer and a shorter than expected lifespan predicted on the basis of their body size for muroid rodents (Hulbert et al. 2007).

Despite the caveats outlined above, comparing the longlived naked mole-rat to its similarly sized, shorter-lived mouse counterpart reveals a number of phenotypic differences between species (Table 4) that appear to be likely candidates pertinent to both aging studies and key age-associated diseases. These interspecific differences are linked to oxidative stress response, genomic maintenance, and proteostasis.

\section{Genomic and transcriptomic comparisons of specific biochemical pathways}

\section{Oxidative damage}

Transcriptome analyses revealed that mitochondrial, oxidoreduction, and fatty acid metabolism pathways are upregulated in naked mole-rats with respect to mice ( $\mathrm{Yu}$ et al. 2011). Paradoxically, tissues from captive naked molerats have high levels of oxidative damage to lipids, proteins, and DNA from an early age (Andziak and Buffenstein 2006; Andziak et al. 2006; Buffenstein et al. 2008). Not 
Table 4 Phenotypic differences between naked mole-rats and mice

\begin{tabular}{|c|c|}
\hline Phenotype/Pathway & Naked mole-rat vs. Mouse (C57B1/6) \\
\hline Oxidative damage & $\uparrow$ \\
\hline Antioxidant levels & $\rightarrow$ \\
\hline Cytoprotective [NRF2] signaling activity & $\uparrow$ \\
\hline Genome maintenance (DNA repair) & $\uparrow$ \\
\hline Cancer incidence & $\downarrow$ \\
\hline Telomere length & $\downarrow$ \\
\hline Telomerase & $\downarrow$ \\
\hline Tolerance of hypoxia and hypercapnia & $\uparrow$ \\
\hline mTOR signaling & $\downarrow$ \\
\hline Proteome maintenance & $\uparrow$ \\
\hline Autophagy & $\uparrow$ \\
\hline Proteasome activity & $\uparrow$ \\
\hline \multicolumn{2}{|c|}{$\begin{array}{l}\text { Naked mole-rats are extraordinarily long-lived compared to the similarly sized mouse. Many previous } \\
\text { studies have started to characterize aging-related phenotypes in the naked mole-rat. Compared to shorter- } \\
\text { lived mice (i.e., C57B1/6), naked mole-rats are cancer resistant and tolerant of exogenous stressors } \\
\text { including hypoxia and hypercapnia. They also have elevated proteome and genome maintenance, autop- } \\
\text { hagy, and proteasome activity levels compared to mice. Strikingly, they have high levels of oxidative } \\
\text { damage even from a young age compared to mice, and both species have similar levels of antioxidant } \\
\text { enzymes (i.e., SOD). Despite this, naked mole-rats have high constitutive levels of cytoprotective NRF2- } \\
\text { signaling activity. This may be one critical pathway that contributes to their lengthened healthspan and } \\
\text { lifespan }\end{array}$} \\
\hline
\end{tabular}

surprisingly, these damage levels are paired with a lackluster antioxidant defense. Naked mole-rats have similar levels of key antioxidant enzymes to those of mice, with the exception of cytosolic glutathione peroxidase [cGPX], which is 70-fold lower in naked mole-rats (Andziak et al. 2005; Lewis et al. 2013). Transcriptomic studies confirm that both Gpxl and Gpx4 are lower in naked mole-rats compared to mice (Yu et al. 2011). Additionally, two of the six peroxiredoxins (Prdx2 and Prdx5) are expressed at lower levels than observed in mice both at the transcript and protein level (Fang et al. 2014). Despite the low levels of antioxidant expression, naked mole-rats (and other long-lived rodents including the blind mole-rat) do have elevated levels of other cytoprotective pathways (e.g., NRF2, molecular chaperones) compared to the mouse (Edrey et al. 2014; Rodriguez et al. 2014; Lewis et al. 2015).

\section{Genome maintenance and cancer resistance}

A global comparison of previously known human cancer-associated oncogenes and tumor suppressors in the naked molerat genome did not reveal any striking difference in copy number variation (MacRae et al. 2015). Rather, a lower frequency of mutations has been observed in a subset of 518 genes linked to genome maintenance in naked mole-rats, mice, and humans (MacRae et al. 2015), which may suggest that positive selection is acting on this gene group. Consistently, many of the enzymes directly pertinent to regulating DNA repair are expressed at higher levels in liver, brain, and testes than observed in mice (Kim et al. 2011; MacRae et al. 2015), including enzymes involved in tumor suppression (e.g., TP53), base excision repair, mismatch repair, and nonhomologous end-joining (MacRae et al. 2015). It has been thought that increased levels of p16 were associated with the "contact inhibition phenomenon" observed in naked mole-rat primary cultures of dermal fibroblasts in some laboratories (Seluanov et al. 2009). Further analysis of the INK4 locus revealed unique splicing patterns that encodes an additional protein, pALT $^{\mathrm{INK4a/b}}$, which may contribute to cell cycle regulation and cancer resistance in naked mole-rats (Tian et al. 2015). Indepth genome analysis revealed that the p16INK4a may be altered in structure, producing a smaller protein with earlier stop codons (14-kDa) (Kim et al. 2011), that may also impact cell cycle progression and tumorigenesis.

Intriguingly, the distantly related, but nonetheless cancer-resistant blind mole-rat (Spalax ehrenbergi; Table 1) has purportedly evolved different anticancer mechanisms to that of the naked mole-rat (Manov et al. 2013). p53 in Spalax differs from that of most mammals with a change in amino acid sequence akin to a specific mutation frequently found in tumors (Shams et al. 2013). This subtle difference in p53 protein is not without major consequence; it alters the ability of this species to induce apoptosis and enhances the immune-inflammatory processes promoting interferon B1-induced necrosis (Shams et al. 2013). In contrast, the naked mole-rat p53 does not show this potentially beneficial mutation (Gorbunova et al. 2014), but is more similar to that of humans than that of mice and rats with similar proline-rich domains that reportedly have been subject to positive selection (Keane et al. 2014). 


\section{Telomeres and telomerase}

A number of genes in the naked mole-rat genome have undergone positive selection, including genes involved in the function and regulation of telomerase (Tepl and Terf1) (Yu et al. 2011). Telomere shortening is thought to play a pivotal role in aging and as they reach critically short length, cells enter a senescent state. Studies evaluating telomere length and telomerase activity have produced equivocal and contradictory findings [(Seluanov et al. 2007; Gomes et al. 2011); Yang, Hornsby and Buffenstein pers. com]. Gomes et al. 2011 reported the telomeres of naked mole-rats to be much smaller (one-third to one half) than those of lab mice and rats, and of similar length to those in humans (Gomes et al. 2011), with telomerase activity in cultured naked mole-rat dermal fibroblasts just one-third of what is observed in mouse fibroblasts (Gomes et al. 2011). The naked mole-rat telomerase genes have unique polymorphisms and promoter structure (compared to guinea pigs and humans) (Evfratov et al. 2014). Tepl, Terfl, and other genes that regulate telomerase activity likely also contribute to the slow-aging and cancer-resistant phenotype of the naked mole-rat (Yu et al. 2011).

\section{Tolerance of hypoxia, hypercapnia, ammonia, and pain}

Naked mole-rats (as well as other subterranean mole-rat species) evolved to live successfully in a sealed maze of hypoxic underground tunnels where gas exchange through soil is poor. Transcriptomic differences relative to mice and rats are evident in all three subterranean species of mole-rats even under normoxia (Fang et al. 2014). For example, hemoglobin $\alpha$ ( $\mathrm{Hbal}$ and $\mathrm{Hba2}$ ) and neuroglobin $(\mathrm{Ngb})$ are more highly expressed in the mole-rats (Avivi et al. 2010; Fang et al. 2014). Both naked mole-rat and guinea pig hemoglobin $\alpha$ share a unique amino acid change (Pro44His) thought to convey better tolerance of hypoxia in the low-oxygen atmospheres encountered underground and at high altitudes, respectively (Fang et al. 2014). Hypercapnia is deadly to most mammals and generally evokes considerable pain; increased levels of $\mathrm{CO}_{2}$ turns air acidic, stimulating pain receptors and the burning sensation in nasal passages and eyes (Brand et al. 2010). The lack of pain response in naked mole-rats is attributed to motif changes in the $\mathrm{Na}(\mathrm{V}) 1.7$ sodium channel $(\operatorname{Scn} 9 a)$, a feature shared with Damaraland and blind mole-rats, as well as other species that are chronically subjected to similar atmospheric conditions (Fang et al. 2014), as well as the lack of expression in substance $\mathrm{P}$ and calcitonin gene-related gene peptide (Cgrp) (Park et al. 2008; Park and Buffenstein 2012). This difference in the sequence, and most likely subsequent negative regulation, could account for their indifference to chemical induced pain (Kim et al. 2011; Park and Buffenstein 2012).

\section{Insulin and mTOR signaling}

The insulin and mTOR pathways are considered key players in mouse and human aging, with downregulation in these pathways and/or altered signaling through mutations of receptors linked to increased longevity (Selman et al. 2008; Selman and Withers 2011; Lamming and Sabatini 2011; Johnson et al. 2013; Lamming et al. 2013; Mulvey et al. 2014). Transcriptomic analyses revealed that the naked mole-rat showed a divergent sequence of the insulin $\beta$-chain, similar to that of the guinea pig and other close relatives, i.e., hystricognath rodents (Opazo et al. 2005). Moreover, RNAseq using both liver and brain tissue taken from nonfasted, non stressed animals show that many components of the insulin and mTOR pathways are downregulated and might be indicative of slower growth rates (Kim et al. 2011). Both insulin and insulin receptor gene expression are attenuated, in addition to insulin receptor substrate 1 (Irs 1 ). Furthermore, Pi3 $k$ isoforms are also downregulated (with the exception of Pik3cb) (Kim et al. 2011), as well as Igfl and Igfl receptor (Igflr) (Kim et al. 2011). Alternatively, insulin like growth factor 2 (Igf2) transcript levels are high (Kim et al. 2011). Igf2 has high homology with insulin and is commonly expressed at high levels in utero with levels dropping dramatically after birth (Lui and Baron 2013). Igf2, and its binding protein $I g f 2 b p 2$, are retained at high levels in adult naked mole-rats (Kim et al. 2011), thereby maintaining a neonatal like mode of glucose handling and most likely remaining highly sensitive to different nutrient signals. The Igfbp protease, pregnancy-associated plasma protein-A (Papp-a), known to modulate mouse lifespan, reportedly has a different sequence in the naked mole-rat to that of mice and is also constitutively expressed at low levels, giving rise to abnormal glucose tolerance tests (Kramer and Buffenstein 2004; Brohus et al. 2015) and raising the possibility that Papp- $a$ may play a role in naked mole-rat longevity.

\section{Proteome maintenance}

The observed decline in nutrient-sensing gene expression described above may have a profound effect on protein translation and turnover. The proteostasis system of the naked mole-rat is significantly more robust than that of mice (Pride et al. 2015). Naked mole-rats exhibit greater translational fidelity apparently without a reduction in translation rate (Azpurua et al. 2013); their proteins also appear to be more resistant to oxidation, heat, and urea (Perez et al. 2009). This greater structural stability is maintained with age (Perez et al. 2009). Autophagy is also 
elevated and sustained during aging in the naked mole-rat (Rodriguez et al. 2011; Pride et al. 2015) and doublemembrane autophagosomes have been observed in higher numbers in multiple tissues of naked mole-rats (Zhao et al. 2014) compared to mice. Proteasome activity in multiple tissues was found to be significantly higher in naked molerats than in shorter-lived mice (Perez et al. 2009; Rodriguez et al. 2012; Edrey et al. 2014) and also exceptionally resistant to inhibition by competitive inhibitors MG-132 and bortezomib and oxidative stress (Rodriguez et al. 2014). Interestingly, it appears that the African and Middle Eastern mole-rats have higher levels of proteasome activity than above-ground-dwelling rodents, and that the level of chymotrypsin and caspase-like activity in muscle tissues significantly correlate well with maximum lifespan (Rodriguez et al. 2016).

\section{Challenges of comparative genomics}

Multiple mammalian genomes have been sequenced and assembled in the recent decades. However, the information that would enable robust comparative genomic analyses is still sparse. As of today, only 19 rodent genomes have been assembled with varying levels of quality, and most sequenced species are only distantly related to the naked mole-rat. The ideal comparative genomic study would include a large number of species as well as multiple individuals within each species to account for intraspecific genetic variation. This limitation in numbers of genomes and their disparate quality makes linking variation in sequence to a specific phenotype more of an anecdotal, rather than data-driven, task.

Comparative genomic studies assessing interspecific differences in genomic data sets present numerous problems. Of critical importance is the choice of the reference genome, with the trade-off being whether to choose a closely related species that is not well annotated or that of a more distantly related species that has been extensively studied and is well annotated. For example, while mice and humans have been extremely well studied, they diverged from mole-rats $\sim 70$ and $\sim 90$ mya respectively (Kim et al. 2011). The genomes of the more closely related guinea pig (divergence of $\sim 39.5$ mya) and the Damaraland mole-rat (divergence of $\sim 31.2$ mya) have also been assembled, albeit with lower quality and poorer annotation than that of mice and humans. Possibly because of extensive deep sequence analyses of the human genome, the naked molerat genome shows the best homology to that of humans, rather than with other rodents.

In species with poor coverage or poorly annotated genomes, it is particularly difficult to identify genes that

Table 5 Hypothesis-driven approaches to comparative genomic study design

\begin{tabular}{|c|c|c|c|}
\hline Organism & Condition & Phenotype & References \\
\hline S. cerevisiae & ubr $2 \Delta$ & Increased replicative lifespan & $\begin{array}{l}\text { Kruegel et al. } \\
\text { (2011) }\end{array}$ \\
\hline S. cerevisiae & $\operatorname{rpn} 4 \Delta$ & Decreased replicative lifespan & $\begin{array}{l}\text { Kruegel et al. } \\
\text { (2011) }\end{array}$ \\
\hline D. melanogaster & RPN11 overexpression & Increased lifespan & $\begin{array}{l}\text { Tonoki et al. } \\
\text { (2009) }\end{array}$ \\
\hline C. elegans & $\begin{array}{l}\text { Knockdown of rpn- } 1 \text {, rpn-3, rpn- } 6 \text {, rpn- } 7 \text {, rpn- } 8 \text {, rpn- } 9 \text {, } \\
\text { rpn- } 11 \text {, rpt- } 1 \text {, rpt- } 4 \text {, rpt-5, rpt- } 6 \text {, pas-5, pas- } 6 \text {, pbs- } 2 \text {, pbs- } \\
\text { 3, pbs- } 4 \text {, pbs-5, or pbs- } 7\end{array}$ & Decreased lifespan & $\begin{array}{l}\text { Ghazi et al. } \\
\text { (2007) }\end{array}$ \\
\hline C. elegans & pbs-5 overexpression & Increased lifespan & $\begin{array}{l}\text { Chondrogianni } \\
\text { et al. (2015) }\end{array}$ \\
\hline M. musculus & Pac1 knockout & $\begin{array}{l}\text { Early embryonic lethality, } \\
\text { decrease in free } 20 \mathrm{~S} \text { proteasome, } \\
\text { premature senescence }\end{array}$ & $\begin{array}{l}\text { Sasaki et al. } \\
\text { (2010) }\end{array}$ \\
\hline M. musculus & Psmc1 knockdown in brain & $\begin{array}{l}\text { Protein aggregation and } \\
\text { neurodegeneration }\end{array}$ & $\begin{array}{l}\text { Bedford et al. } \\
\text { (2008) }\end{array}$ \\
\hline H. sapiens (WI-38) & Lactacystin treatment & Reduces RLS & $\begin{array}{l}\text { Torres et al. } \\
\text { (2006) }\end{array}$ \\
\hline H. glaber & Unknown & Unknown & Unknown \\
\hline
\end{tabular}

Perturbations to genes related to the proteasome, as well as the proteasome itself, result in changes to lifespan and healthspan of a variety of organisms, including yeasts, worms, flies, mice, and even humans. The long-lived naked mole-rat also has elevated proteasome activity, but we have little information about the genes involved. Thus, by interrogating the genome specifically for proteasome-related genes, we can study these genes more in depth and compare with other species, to identify beneficial (or detrimental) mutations or polymorphisms. Differences in gene/ protein sequence can then be studied in vitro or in vivo to identify causal variants. [References in Table: Torres et al. (2006), Bedford et al. (2008), Sasaki et al. (2010), Chondrogianni et al. (2015)] 


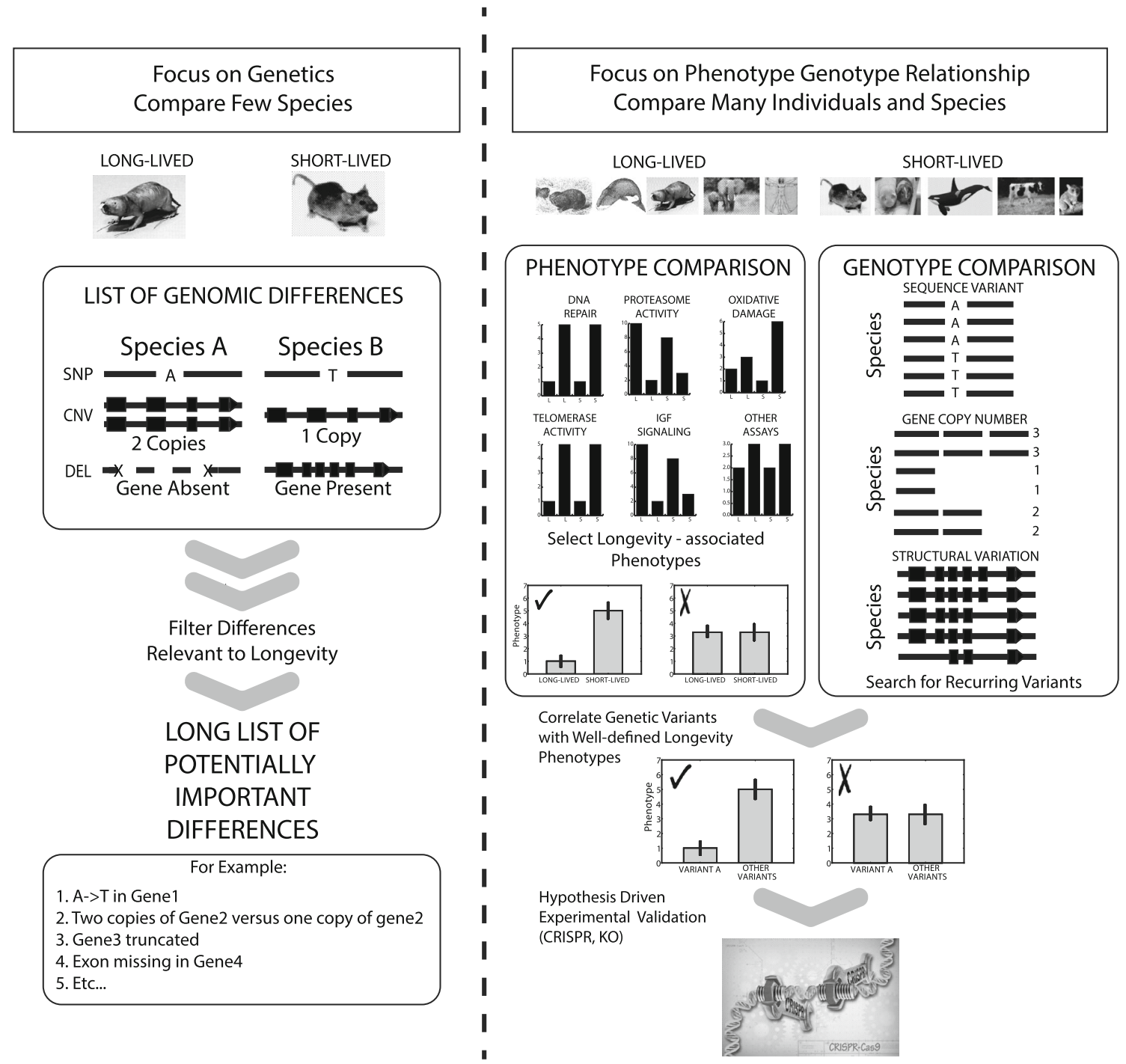

Fig. 5 A summary of future project directions. Current comparative genomic studies usually compare 1 long-lived and 1 short-lived species (i.e., the naked mole-rat vs. the mouse) and result in a large number of genes that may or may not involved in healthspan and/or longevity that have not been experimentally validated. We propose that comparing the genomes of a large number of both long- and

are truly under-expressed, orthologs, and/or splice variants. Data analyses are thus limited to those genes with unambiguous annotation. Focusing comparisons on more closely related species could control for much of the confounding genetic diversity. For example, the recent paper comparing transcriptomes of nine African mole-rat species (Davies et al. 2015) is probably the best comparative genomic study using the naked mole-rat to date. This genome-wide screen suggested that genes related to tumor suppression, telomere regulation, cell division, DNA repair, and stress response were under positive selection in the African mole-rat clade (Davies et al. 2015). This provides further mechanistic

short-lived species and focusing on specific phenotypes that may contribute to the extended healthspan and lifespan would yield more focused and meaningful genome data. These results would then be confirmed through hypothesis-driven experimental validation to determine further impact on longevity

insight into what may contribute to their notable cancer and stress resistance, and whether these gene expression patterns are unique to the naked mole-rat or shared among closely related species.

Given the large evolutionary distance of the genomes usually compared, finding the causal variation for a phenotype has to be hypothesis driven and requires careful scrutiny and interpretation, for observed species differences likely reflect more about their evolutionary history, ecophysiological traits, or divergent phylogeny. This would certainly be the case if one compared the genomes of the long-lived Bowhead whale directly to the long-lived naked 
mole-rat. While it is tempting to force hypotheses to fit a priori predictions, this approach often may give rise to spurious “just-so stories." Two clear examples were recently highlighted: In the original naked mole-rat genome paper (Kim et al. 2011) the "hairless" phenotype of naked mole-rats was attributed to a substitution of conserved amino acid in the identified hair growth associated protein (HR). This interpretation was based on findings that similar mutations in this particular codon cause hair loss in mice, rats, and humans. However, two other hystricognath rodents, namely the Damaraland mole-rat and guinea pig, share this mutation in the HR gene, yet have hairy coats (Delsuc and Tilak 2015). It therefore becomes clear that differences in the mole-rat and mouse/human HR gene simply reflect a phylogenetic divergence from mice and men (Delsuc and Tilak 2015; Davies et al. 2015).

The conclusion concerning hyaluronan synthase 2 (Has2) is another such example. Differences in Has 2 have been used as a causal explanation for the extraordinarily low incidence of cancer in naked mole-rats (Seluanov et al. 2009; Tian et al. 2013). Unique amino acid residues in this enzyme reportedly result in the synthesis of a higher molecular weight hyaluronan in naked mole-rats than in mice (Tian et al. 2013). While the Has 2 sequence is unique to the naked mole-rat, extending comparisons to a wide range of other species showed that some of the proposed mutations are shared with several species, including guinea pigs. These mutations do not always result in cancer resistance (Faulkes et al. 2015), although their specific functional ramifications are unknown. Interestingly, high molecular mass hyaluronan is also reportedly expressed in the blind mole-rat (Spalax galili) (Tian et al. 2013) despite the fact it does not share any of the significant mutations observed in the naked mole-rat yet reportedly is resistant to cancer (Manov et al. 2013).

\section{Correlation of phenotype and genotype}

As discussed above, one of the confounding factors for the comparative genomics analyses is poor definition of the phenotype to be explained. Longevity itself is not a welldefined phenotype, but a byproduct of a myriad of beneficial phenotypes and/or the absence of detrimental phenotypes including cancer resistance and better cellular and proteome maintenance. Genomics, overall, is still a descriptive science when comparing one entire genome to another the data will be overwhelming and less likely to identify or target specific mechanisms. We suggest that defining the phenotypes conserved between long-lived species (i.e., diverged from short-lived species) could be a major step forward. For instance, when the phenotype is well defined, as in the case of different rRNA processings in naked mole-rats that results in a different structure of the 28S ribosomal subunit (Azpurua et al. 2013; Fang et al. 2014), the comparisons are limited to a subset of genes and suggest meaningful genotype-phenotype connections.

In another example, data across many species (including worms and flies) indicate that proteasome function is critical to lifespan, and may also promote extended healthspan and longevity-related phenotypes (Ghazi et al. 2007; Tonoki et al. 2009; Kruegel et al. 2011). Previous data have also shown that increased proteasome activity is observed in naturally long-lived species (Pickering et al. 2015), including the naked mole-rat (Rodriguez et al. 2012, 2016), although we know nothing about the genetic mechanisms behind these phenotypes. By interrogating the genomic data for specific, proteasome-related genes (Table 5), we can get a more in-depth picture of not only those specific gene sequences, but also how small differences may impact this longevity-related phenotype, and experimentally test causality of these genetic differences, using tools like CRISPR, in vitro and/or in vivo (Fig. 5).

Another approach to better define the phenotype of increased lifespan includes measuring the transcriptomic and proteomic responses of long-lived and short-lived species to a similar battery of perturbations. For instance, to better define the phenotype of cancer resistance of the naked mole-rat, one could examine differences in the transcriptional response to cancer-causing agents between the cancer-resistant and cancer-prone species. This approach will enable identification of genes, pathways, or regulatory molecules that are differentially regulated between long-lived and short-lived species, focusing the comparative genomic query to find the variation that is causal for this change.

Finally, genetic differences that can generate significant phenotypic variation between even closely related species are postulated to be a result of regulatory, and not coding, sequence changes [reviewed in Varki and Altheide (2005)]. Better annotation of regulatory sequences in the species of interest (e.g., chromatin profiling) could make linking the genetic variation to phenotypic difference easier.

In summary, technological improvements will provide us with genomic data of far greater resolution than what is available today. Similarly, more carefully controlled comparative studies using state-of-the-art bioinformatics tools will yield high-quality, unambiguous data. As a direct result of these improvements, greater insights into the unique traits of naked mole-rat will become possible, particularly when combined with phenotypic profiling. Improving access to the secrets within the naked mole-rat genome will elucidate the mechanisms naked mole-rats employ to resist the vagaries of aging and prevent ageassociated diseases from gaining hold. 
Acknowledgments We thank David Botstein and Cynthia Kenyon for constructive criticism of this manuscript. In addition we thank an anonymous reviewer for suggesting we examine overlap with the Bowhead whale and their other constructive comments.

Open Access This article is distributed under the terms of the Creative Commons Attribution 4.0 International License (http://creativecommons.org/licenses/by/4.0/), which permits unrestricted use, distribution, and reproduction in any medium, provided you give appropriate credit to the original author(s) and the source, provide a link to the Creative Commons license, and indicate if changes were made.

\section{References}

Alfoldi J, Lindblad-Toh K (2013) Comparative genomics as a tool to understand evolution and disease. Genome Res 23:1063-1068. doi:10.1101/gr.157503.113

An JH, Blackwell TK (2003) SKN-1 links C. elegans mesendodermal specification to a conserved oxidative stress response. Genes Dev 17:1882-1893. doi:10.1101/gad.1107803

Andziak B, Buffenstein R (2006) Disparate patterns of age-related changes in lipid peroxidation in long-lived naked mole-rats and shorter-lived mice. Aging Cell 5:525-532. doi:10.1111/j.14749726.2006.00246.x

Andziak B, O'Connor TP, Buffenstein R (2005) Antioxidants do not explain the disparate longevity between mice and the longestliving rodent, the naked mole-rat. Mech Ageing Dev 126:1206-1212. doi:10.1016/j.mad.2005.06.009

Andziak B, O'Connor TP, Qi W et al (2006) High oxidative damage levels in the longest-living rodent, the naked mole-rat. Aging Cell 5:463-471. doi:10.1111/j.1474-9726.2006.00237.x

Austad SN (2009) Comparative biology of aging. J Gerontol A 64A:199-201. doi:10.1093/gerona/gln060

Avivi A, Gerlach F, Joel A et al (2010) Neuroglobin, cytoglobin, and myoglobin contribute to hypoxia adaptation of the subterranean mole rat Spalax. Proc Natl Acad Sci USA 107:21570-21575. doi:10.1073/pnas.1015379107

Azpurua J, Ke Z, Chen IX et al (2013) Naked mole-rat has increased translational fidelity compared with the mouse, as well as a unique $28 \mathrm{~S}$ ribosomal RNA cleavage. Proc Natl Acad Sci USA 110:17350-17355. doi:10.1073/pnas.1313473110

Bedford L, Hay D, Devoy A et al (2008) Depletion of 26S proteasomes in mouse brain neurons causes neurodegeneration and Lewy-like inclusions resembling human pale bodies. J Neurosci 28:8189-8198. doi:10.1523/JNEUROSCI.2218-08.2008

Begall S, Burda H, Schleich CE (2007) Subterranean Rodents. Springer Science \& Business Media, Berlin

Bennett NC, Faulkes CG (2000) African mole-rats. Cambridge University Press, Cambridge

Bens M, Sahm A, Groth M et al (2016) FRAMA: from RNA-seq data to annotated mRNA assemblies. BMC Genomics 17:1. doi:10. $1186 / \mathrm{s} 12864-015-2349-8$

Blass GR (2014) Extreme resistance to hypercapnia-induced pulmonary edema of the African naked mole-rat. University of Illinois at Chicago, $\mathrm{PhD}$ dissertation, http://www.the-scientist. com/?articles.view/articleNo/32136/title/UndergroundSupermodels/

Bozina KD (1961) How long does the queen live. Pchelovodstvo 38(6): 13

Brand A, Smith ESJ, Lewin GR, Park TJ (2010) Functional neurokinin and NMDA receptor activity in an animal naturally lacking substance P: the naked mole-rat. PLoS One 5:e15162. doi:10.1371/journal.pone.0015162
Brohus M, Gorbunova V, Faulkes CG et al (2015) The insulin-like growth factor system in the long-lived naked mole-rat. PLoS One 10:e0145587. doi:10.1371/journal.pone.0145587

Brown-Borg HM, Brown-borg KE, Meliska CJ, Bartke A (1996) Dwarf mice and the aging process. Nature 384:33

Brutovská E, Sámelová A, Dušička J, Mičieta K (2013) Ageing of trees: application of general ageing theories. Ageing Res Rev 12:855-866. doi:10.1016/j.arr.2013.07.001

Buffenstein R (2005) The naked mole-rat: a new long-living model for human aging research. J Gerontol A 60:1369-1377. doi:10. 1093/gerona/60.11.1369

Buffenstein R (2008) Negligible senescence in the longest living rodent, the naked mole-rat: insights from a successfully aging species. J Comp Physiol B 178:439-445. doi:10.1007/s00360007-0237-5

Buffenstein R, Edrey YH, Yang T, Mele J (2008) The oxidative stress theory of aging: embattled or invincible? Insights from nontraditional model organisms. AGE 30:99-109. doi:10.1007/ s11357-008-9058-Z

Buffenstein R, Nelson OL, Corbit KC (2014) Questioning the preclinical paradigm: natural, extreme biology as an alternative discovery platform. Aging 6:913-920

Burge CB, Karlin S (1998) Finding the genes in genomic DNA. Curr Opin Struct Biol 8:346-354

Butler PG, Wanamaker AD Jr, Scourse JD et al (2013) Variability of marine climate on the North Icelandic Shelf in a 1357-year proxy archive based on growth increments in the bivalve Arctica islandica. Palaeogeogr Palaeoclimatol Palaeoecol 373:141-151. doi:10.1016/j.palaeo.2012.01.016

Carey JR (2002) Longevity minimalists: life table studies of two species of northern Michigan adult mayflies. 37:567-670

Cernuda-Cernuda R, DeGrip WJ, Cooper HM et al (2002) The retina of Spalax ehrenbergi: novel histologic features supportive of a modified photosensory role. Invest Ophthalmol Vis Sci 43:2374-2383

Chaisson MJP, Huddleston J, Dennis MY et al (2015) Resolving the complexity of the human genome using single-molecule sequencing. Nature 517:608-611. doi:10.1038/nature13907

Chen H-Y, Maklakov AA (2012) Longer life span evolves under high rates of condition-dependent mortality. Curr Biol 22:2140-2143. doi:10.1016/j.cub.2012.09.021

Cheung J, Estivill X, Khaja R et al (2003) Genome-wide detection of segmental duplications and potential assembly errors in the human genome sequence. Genome Biol 4:R25

Chondrogianni N, Georgila K, Kourtis N et al (2015) 20S proteasome activation promotes life span extension and resistance to proteotoxicity in Caenorhabditis elegans. FASEB J 29:611-622. doi:10.1096/fj.14-252189

Clancy DJ, Gems D, Harshman LG et al (2001) Extension of life-span by loss of CHICO, a Drosophila insulin receptor substrate protein. Science 292:104-106. doi:10.1126/science.1057991

Clarke FM, Faulkes CG (1997) Dominance and queen succession in captive colonies of the eusocial naked mole-rat, Heterocephalus glaber. Proc R Soc B 264:993-1000. doi:10.1098/rspb.1997. 0137

Collins CR, Kays RW (2014) Patterns of mortality in a wild population of white-footed mice. 21:323-336. doi:10.1656/045. 021.0213

Consortium IHGS (2004) Finishing the euchromatic sequence of the human genome. Nature 431:931-945. doi:10.1038/nature03001

Craig George JC, Bockstoce JR (2008) Two historical weapon fragments as an aid to estimating the longevity and movements of bowhead whales. Polar Biol 31:751-754. doi:10.1007/s00300008-0407-2

Davies KTJ, Bennett NC, Tsagkogeorga G et al (2015) Family wide molecular adaptations to underground life in african mole-rats 
revealed by phylogenomic analysis. Mol Biol Evol 32:3089-3107. doi:10.1093/molbev/msv175

Delaney MA, Ward JM, Walsh TF et al (2016) Initial case reports of cancer in naked mole-rats (Heterocephalus glaber). Vet Pathol. doi: $10.1177 / 0300985816630796$

Delsuc F, Tilak M-K (2015) Naked but not Hairless: the pitfalls of analyses of molecular adaptation based on few genome sequence comparisons. Genome Biol Evol 7:768-774. doi:10.1093/gbe/evv036

Du K, Yang L, He S (2015) Phylogenomic analyses reveal a molecular signature linked to subterranean adaptation in rodents. BMC Evol Biol 15:287. doi:10.1186/s12862-015-0564-1

Edrey YH, Hanes M, Pinto M et al (2011a) Successful aging and sustained good health in the naked mole rat: a long-lived mammalian model for biogerontology and biomedical research. ILAR J 52:41-53. doi:10.1093/ilar.52.1.41

Edrey YH, Park TJ, Kang H et al (2011b) Endocrine function and neurobiology of the longest-living rodent, the naked molerat. Exp Gerontol 46:116-123. doi:10.1016/j.exger.2010.09. 005

Edrey YH, Oddo S, Cornelius $\mathrm{C}$ et al (2014) Oxidative damage and amyloid- $\beta$ metabolism in brain regions of the longest-lived rodents. J Neurosci Res 92:195-205. doi:10.1002/jnr.23320

Evfratov SA, Smekalova EM, Golovin AV et al (2014) Structural features of the telomerase RNA gene in the naked mole rat Heterocephalus glaber. Acta Nat 6:21

Fang X, Seim I, Huang Z et al (2014) Adaptations to a subterranean environment and longevity revealed by the analysis of mole rat. Genomes 8:1354-1364. doi:10.1016/j.celrep.2014.07.030

Faulkes CG, Bennett NC, Bruford MW et al (1997) Ecological constraints drive social evolution in the African mole-rats. Proc R Soc B 264:1619-1627. doi:10.1098/rspb.1997.0226

Faulkes CG, Verheyen E, Verheyen W et al (2004) Phylogeographical patterns of genetic divergence and speciation in African molerats (Family: Bathyergidae). Mol Ecol 13:613-629. doi:10.1046/ j.1365-294X.2004.02099.x

Faulkes CG, Davies KTJ, Rossiter SJ, Bennett NC (2015) Molecular evolution of the hyaluronan synthase 2 gene in mammals: implications for adaptations to the subterranean niche and cancer resistance. Biol Lett 11:20150185. doi:10.1098/rsbl.2015.0185

Finch CE, Kirkwood TBL (2000) Chance, development, and aging. Oxford University Press, Oxford

Fraga MF, Ballestar E, Paz MF et al (2005) Epigenetic differences arise during the lifetime of monozygotic twins. PNAS 102:10604-10609. doi:10.1073/pnas.0500398102

Friedman DB, Johnson TE (1988) Mutation in the age-1 gene in Caenorhabditis elegans lengthens life and reduces hermaphrodite fertility. Genetics 118:75-86

Gems D, Partridge L (2013) Genetics of longevity in model organisms: debates and paradigm shifts. Annu Rev Physiol 75:621-644. doi:10.1146/annurev-physiol-030212-183712

Ghazi A, Henis-Korenblit S, Kenyon C (2007) Regulation of Caenorhabditis elegans lifespan by a proteasomal E3 ligase complex. PNAS 104:5947-5952. doi:10.1073/pnas.0700638104

Gnerre S, MacCallum I, Przybylski D et al (2011) High-quality draft assemblies of mammalian genomes from massively parallel sequence data. Proc Natl Acad Sci USA 108:1513-1518. doi:10. 1073/pnas.1017351108

Gomes NMV, Ryder OA, Houck ML et al (2011) Comparative biology of mammalian telomeres: hypotheses on ancestral states and the roles of telomeres in longevity determination 10:761-768. doi:10.1111/j.1474-9726.2011.00718.x

Gorbunova V, Seluanov A, Zhang Z et al (2014) Comparative genetics of longevity and cancer: insights from long-lived rodents. Nat Rev Genet 15:531-540

Grimes KM, Lindsey ML, Gelfond JAL, Buffenstein R (2012) Getting to the heart of the matter: age-related changes in diastolic heart function in the longest-lived rodent, the naked mole rat. J Gerontol A 67:384-394. doi:10.1093/gerona/glr222

Grimes KM, Reddy AK, Lindsey ML, Buffenstein R (2014) And the beat goes on: maintained cardiovascular function during aging in the longest-lived rodent, the naked mole-rat. Am J Physiol 307:H284-H291. doi:10.1152/ajpheart.00305.2014

Hamilton WD (1966) The moulding of senescence by natural selection. J Theor Biol 12:12-45. doi:10.1016/00225193(66)90184-6

Herndon LA, Schmeissner PJ, Dudaronek JM et al (2002) Stochastic and genetic factors influence tissue-specific decline in ageing $C$. elegans. Nature 419:808-814. doi:10.1038/nature01135

Hölldobler B, Wilson EO (1990) The ants. Harvard University Press, Cambridge

Howell DE, Usinger RL (1933) Observations on the flight and length of life of drone bees. Ann Entomol Soc Am 26:239-246. doi:10. 1093/aesa/26.2.239

Hulbert AJ, Pamplona R, Buffenstein R, Buttemer WA (2007) Life and death: metabolic rate, membrane composition, and life span of animals. Physiol Rev 87:1175-1213. doi:10.1152/physrev. 00047.2006

Ikeno Y, Hubbard GB, Lee S et al (2009) Reduced incidence and delayed occurrence of fatal neoplastic diseases in growth hormone receptor/binding protein knockout mice. J Gerontol A 64:522-529. doi:10.1093/gerona/glp017

Jacob F (1977) Evolution and Tinkering. Science 196:1161-1166

Jarvis JU (1981) Eusociality in a mammal: cooperative breeding in naked mole-rat colonies. Science 212:571-573. doi:10.1126/ science. 7209555

Jiang JC (2000) An intervention resembling caloric restriction prolongs life span and retards aging in yeast. FASEB J. doi:10. 1096/fj.00-0242fje

Johnson SC, Rabinovitch PS, Kaeberlein M (2013) mTOR is a key modulator of ageing and age-related disease. Nature 493:338-345. doi:10.1038/nature11861

Jorgensen CB (2001) August Krogh and Claude Bernard on basic principles in experimental physiology. BioScience 51(1):1-3

Kapahi P (2010) Protein synthesis and the antagonistic pleiotropy hypothesis of aging. Protein metabolism and homeostasis in aging. Springer, Boston, pp 30-37

Keane M, Craig T, Alföldi J et al (2014) The naked mole rat genome resource: facilitating analyses of cancer and longevity-related adaptations. Bioinformatics 30:3558-3560. doi:10.1093/bioinfor matics/btu579

Keane M, Semeiks J, Webb AE et al (2015) Insights into the evolution of longevity from the bowhead whale genome. Cell Rep 10:112-122. doi:10.1016/j.celrep.2014.12.008

Kenyon C, Chang J, Gensch E et al (1993) A C. elegans mutant that lives twice as long as wild type. Nature 366:461-464

Kim EB, Fang X, Fushan AA et al (2011) Genome sequencing reveals insights into physiology and longevity of the naked mole rat. 479:223-227. doi:10.1038/nature10533

Kirkwood TBL, Melov S (2011) On the programmed/non-programmed nature of ageing within the life history. Curr Biol 21:R701-R707. doi:10.1016/j.cub.2011.07.020

Klass MR (1977) Aging in the nematode Caenorhabditis elegans: major biological and environmental factors influencing life span. Mech Ageing Dev 6:413-429. doi:10.1016/00476374(77)90043-4

Kluyver AJ, Donker HJL (1926) Die Einheit in der Biochemie. Chemie derZelle und Gewebe 13:134-190

Kramer B, Buffenstein R (2004) The pancreas of the naked mole-rat (Heterocephalus glaber): an ultrastructural and immunocytochemical study of the endocrine component of thermoneutral and cold acclimated animals. Gen Comp Endocrinol 139:206-214. doi:10.1016/j.ygcen.2004.09.006 
Kruegel U, Robison B, Dange T et al (2011) Elevated proteasome capacity extends replicative lifespan in Saccharomyces cerevisiae. PLoS Genet 7:e1002253. doi:10.1371/journal.pgen. 1002253

Lacey EA (2000) Life underground. University of Chicago Press, Chicago

Lamming DW, Sabatini DM (2011) A radical role for TOR in longevity. Cell Metab 13:617-618. doi:10.1016/j.cmet.2011.05. 006

Lamming DW, Ye L, Sabatini DM, Baur JA (2013) Rapalogs and mTOR inhibitors as anti-aging therapeutics. J Clin Invest 123:980-989. doi:10.1172/JCI64099

Lander ES, Linton LM, Birren B et al (2001) Initial sequencing and analysis of the human genome. Nature 409:860-921. doi:10. $1038 / 35057062$

Langmead Ben, Salzberg SL (2012) Fast gapped-read alignment with Bowtie 2. Nat Methods 9:357-359. doi:10.1038/nmeth.1923

Larson J, Park TJ (2009) Extreme hypoxia tolerance of naked molerat brain. NeuroReport 20:1634-1637. doi:10.1097/WNR. Ob013e32833370cf

LaVinka PC, Park TJ (2012) Blunted Behavioral and C Fos Responses to Acidic Fumes in the African Naked Mole-Rat. PLoS ONE 7:e45060. doi:10.1371/journal.pone.0045060

Lewis KN, Mele J, Hornsby PJ, Buffenstein R (2012) Stress resistance in the naked mole-rat: the bare essentials-a minireview. Gerontology 58:453-462. doi:10.1159/000335966

Lewis KN, Andziak B, Yang T, Buffenstein R (2013) The naked mole-rat response to oxidative stress: just deal with it. Antioxid Redox Signal 19:1388-1399. doi:10.1089/ars.2012.4911

Lewis KN, Wason E, Edrey YH et al (2015) Regulation of Nrf2 signaling and longevity in naturally long-lived rodents. Proc Natl Acad Sci USA 112:3722-3727. doi:10.1073/pnas. 1417566112

Li R, Zhu H, Ruan J et al (2010) De novo assembly of human genomes with massively parallel short read sequencing. Genome Res 20:265-272. doi:10.1101/gr.097261.109

Liang S, Mele J, Wu Y et al (2010) Resistance to experimental tumorigenesis in cells of a long-lived mammal, the naked molerat (Heterocephalus glaber). Aging Cell 9:626-635. doi:10. 1111/j.1474-9726.2010.00588.x

Liao C-Y, Rikke BA, Johnson TE et al (2010) Genetic variation in the murine lifespan response to dietary restriction: from life extension to life shortening. Aging Cell 9:92-95. doi:10.1111/ j.1474-9726.2009.00533.x

Lui JC, Baron J (2013) Evidence that Igf2 down-regulation in postnatal tissues and up-regulation in malignancies is driven by transcription factor E2f3. Proc Natl Acad Sci USA 110:6181-6186. doi:10.1073/pnas.1219079110

Luo R, Liu B, Xie Y et al (2012) SOAPdenovo2: an empirically improved memory-efficient short-read de novo assembler. GigaScience 1:1-6. doi:10.1186/2047-217X-1-18

MacRae SL, Zhang Q, Lemetre C et al (2015) Comparative analysis of genome maintenance genes in naked mole rat, mouse, and human. Aging Cell 14:288-291

Manov I, Hirsh M, Iancu TC et al (2013) Pronounced cancer resistance in a subterranean rodent, the blind mole-rat, Spalax: in vivo and in vitro evidence. BMC Biol 11:1. doi:10.1186/17417007-11-91

Martin GM (1997) Mechanism of aging? Mol Med 3:356-358

McCay CM, Crowell MF, Maynard LA (1935) The effect of retarded growth upon the length of life span and upon the ultimate body size. J Nutr 10(1):63-79

McIsaac RS, Lewis KN, Gibney PA, Buffenstein R (2016) From yeast to human: exploring the comparative biology of methionine restriction in extending eukaryotic life span. Ann N Y Acad Sci 1363:155-170. doi:10.1111/nyas. 13032
Misra P, Purshottam DK, Goel AK (2015) Welwitschia mirabilisinduction, growth and organization of mature leaf callus. Curr Sci 109:567-571

Monod J (1997) Chance and necessity. Vintage Books, New York

Morris JZ, Tissenbaum HA, Ruvkun G (1996) A phosphatidylinositol-3-OH kinase family member regulating longevity and diapause in Caenorhabditis elegans. Nature 382:536-539

Mulvey L, Sinclair A, Selman C (2014) Lifespan modulation in mice and the confounding effects of genetic background. J Genet Genomics 41:497-503. doi:10.1016/j.jgg.2014.06.002

O'Connor TP, Lee A, Jarvis JUM, Buffenstein R (2002) Prolonged longevity in naked mole-rats: age-related changes in metabolism, body composition and gastrointestinal function. Comp Biochem Physiol A 133:835-842. doi:10.1016/S1095-6433(02)00198-8

Opazo JC, Palma RE, Melo F, Lessa EP (2005) Adaptive evolution of the insulin gene in caviomorph rodents. Mol Biol Evol 22:1290-1298. doi:10.1093/molbev/msi117

O'Riain MJ, Jarvis J, Faulkes CG (1996) A dispersive morph in the naked mole-rat. Nature 380:619-621

Park TJ, Buffenstein R (2012) Underground supermodels. Scientist June 1 st 2012

Park TJ, Lu Y, Jüttner R et al (2008) Selective inflammatory pain insensitivity in the african naked mole-rat (Heterocephalus glaber). PLoS Biol 6:e13. doi:10.1371/journal.pbio.0060013

Partridge L, Gems D (2002) Mechanisms of ageing: public or private? Nat Rev Genet 3:165-175. doi:10.1038/nrg753

Patterson BD, Upham NS (2014) A newly recognized family from the Horn of Africa, the Heterocephalidae (Rodentia: Ctenohystrica). Zool J Linnean Soc 172:942-963. doi:10.1111/zoj.12201

Perez VI, Buffenstein R, Masamsetti V et al (2009) Protein stability and resistance to oxidative stress are determinants of longevity in the longest-living rodent, the naked mole-rat. Proc Natl Acad Sci USA 106:3059-3064. doi:10.1073/pnas.0809620106

Pickering AM, Lehr M, Miller RA (2015) Lifespan of mice and primates correlates with immunoproteasome expression. J Clin Invest 125:2059-2068. doi:10.1172/JCI80514

Pinto M, Jepsen KJ, Terranova CJ, Buffenstein R (2010) Lack of sexual dimorphism in femora of the eusocial and hypogonadic naked mole-rat: a novel animal model for the study of delayed puberty on the skeletal system. Bone 46:112-120. doi:10.1016/j. bone.2009.08.060

Pride H, Yu Z, Sunchu B et al (2015) Long-lived species have improved proteostasis compared to phylogenetically-related shorter-lived species. Biochem Biophys Res Commun 457:669-675. doi:10.1016/j.bbrc.2015.01.046

Reeve HK, Westneat DF, Noon WA et al (1990) DNA "fingerprinting" reveals high levels of inbreeding in colonies of the eusocial naked mole-rat. PNAS 87:2496-2500

Ribbands CR (1964) The behaviour and social life of honeybees. Dover Publications, New York

Rodriguez KA, Wywial E, Perez VI et al (2011) Walking the oxidative stress tightrope: a perspective from the naked mole-rat, the longest-living rodent. Curr Pharm Des 17:2290-2307

Rodriguez KA, Edrey YH, Osmulski P et al (2012) Altered composition of liver proteasome assemblies contributes to enhanced proteasome activity in the exceptionally long-lived naked mole-rat. PLoS ONE 7:e35890. doi:10.1371/journal.pone. 0035890

Rodriguez KA, Osmulski PA, Pierce A et al (2014) A cytosolic protein factor from the naked mole-rat activates proteasomes of other species and protects these from inhibition. Biochim Biophys Acta 1842:2060-2072. doi:10.1016/j.bbadis.2014.07. 005

Rodriguez KA, Valentine JM, Kramer DA et al (2016) Determinants of rodent longevity in the chaperone-protein degradation network. Cell Stress Chaperones. doi:10.1007/s12192-016-0672-x 
Salmon AB, Sadighi Akha AA, Buffenstein R, Miller RA (2008) Fibroblasts from naked mole-rats are resistant to multiple forms of cell injury, but sensitive to peroxide, ultraviolet light, and endoplasmic reticulum stress. J Gerontol A 63:232-241

Sanchez JR, Milton SL, Corbit KC, Buffenstein R (2015) Multifactorial processes to slowing the biological clock: insights from a comparative approach. Exp Gerontol 71:27-37. doi:10.1016/j. exger.2015.08.017

Sasaki K, Hamazaki J, Koike M et al (2010) PAC1 gene knockout reveals an essential role of chaperone-mediated $20 \mathrm{~S}$ proteasome biogenesis and latent $20 \mathrm{~S}$ proteasomes in cellular homeostasis. Mol Cell Biol 30:3864-3874. doi:10.1128/MCB.00216-10

Schirmer M, D'Amore R, Ijaz UZ et al (2016) Illumina error profiles: resolving fine-scale variation in metagenomic sequencing data. BMC Bioinform 17:125. doi:10.1186/s12859-016-0976-y

Seeley TD (1978) Life history strategy of the honey bee, Apis mellifera. Oecologia 32:109-118. doi:10.1007/BF00344695

Selman C, Withers DJ (2011) Mammalian models of extended healthy lifespan. Philos Trans R Soc Lond B 366:99-107. doi:10. 1098/rstb.2010.0243

Selman C, Lingard S, Choudhury AI et al (2008) Evidence for lifespan extension and delayed age-related biomarkers in insulin receptor substrate 1 null mice. FASEB J 22:807-818. doi:10. 1096/fj.07-9261com

Seluanov A, Chen Z, Hine C et al (2007) Telomerase activity coevolves with body mass not lifespan. Aging Cell 6:45-52. doi:10.1111/j.1474-9726.2006.00262.x

Seluanov A, Hine C, Azpurua J et al (2009) Hypersensitivity to contact inhibition provides a clue to cancer resistance of naked mole-rat. Proc Natl Acad Sci USA 106:19352-19357. doi:10. 1073/pnas.0905252106

Shams I, Malik A, Manov I et al (2013) Transcription Pattern of p53targeted DNA repair genes in the hypoxia-tolerant subterranean mole rat spalax. J Mol Biol 425:1111-1118. doi:10.1016/j.jmb. 2013.01.007

Shao Y, Li J-X, Ge R-L et al (2015) Genetic adaptations of the plateau zokor in high-elevation burrows. Sci Rep 5:17262. doi: $10.1038 /$ srep 17262

Sharon D, Tilgner H, Grubert F, Snyder M (2013) A single-molecule long-read survey of the human transcriptome 31:1009-1014. doi: $10.1038 /$ nbt. 2705

She X, Jiang Z, Clark RA et al (2004) Shotgun sequence assembly and recent segmental duplications within the human genome. Nature 431:927-930. doi:10.1038/nature03062

Sherman PW, Jarvis JUM, Alexander RD (1991) The biology of the naked mole-rat. Princeton University Press, Princeton

Smith TF, Waterman MS (1981) Identification of common molecular subsequences. J Mol Biol 147:195-197. doi:10.1016/00222836(81)90087-5

Sternberg PW (2005) Vulval development. The WormBook, http:// wormbook.org/chapters/www_vulvaldev/vulvaldev.html

Sykiotis GP, Bohmann D (2008) Keap1/Nrf2 signaling regulates oxidative stress tolerance and lifespan in drosophila. Dev Cell 14:76-85. doi:10.1016/j.devcel.2007.12.002

Tian X, Azpurua J, Hine C et al (2013) High-molecular-mass hyaluronan mediates the cancer resistance of the naked mole rat. Nature 499:346-349. doi:10.1038/nature12234
Tian X, Azpurua J, Ke Z et al (2015) INK4 locus of the tumorresistant rodent, the naked mole rat, expresses a functional p15/ p16 hybrid isoform. Proc Natl Acad Sci USA 112:1053-1058. doi:10.1073/pnas.1418203112

Tilgner H, Grubert F, Sharon D, Snyder MP (2014) Defining a personal, allele-specific, and single-molecule long-read transcriptome. Proc Natl Acad Sci USA 111:9869-9874. doi:10. 1073/pnas. 1400447111

Tonoki A, Kuranaga E, Tomioka T et al (2009) Genetic evidence linking age-dependent attenuation of the 26S proteasome with the aging process. Mol Cell Biol 29:1095-1106. doi:10.1128/ MCB.01227-08

Torres C, Lewis L, Cristofalo VJ (2006) Proteasome inhibitors shorten replicative life span and induce a senescent-like phenotype of human fibroblasts. J Cell Physiol 207:845-853. doi:10. $1002 /$ jcp. 20630

Valdesalici S, Cellerino A (2003) Extremely short lifespan in the annual fish Nothobranchius furzeri. Proc R Soc B 270:S189S191. doi:10.1098/rsbl.2003.0048

Varki A, Altheide TK (2005) Comparing the human and chimpanzee genomes: searching for needles in a haystack. Genome Res 15:1746-1758. doi:10.1101/gr.3737405

Venter JC, Adams MD, Myers EW et al (2001) The sequence of the human genome. Science 291:1304-1351. doi:10.1126/science. 1058040

Vinogradov AE (2015) Accelerated pathway evolution in mouse-like rodents involves cell cycle control. Mamm Genome 26:609-618. doi:10.1007/s00335-015-9605-8

Wagner A (2002) Selection and gene duplication: a view from the genome. Genome Biol 3:10121-10123

Weindruch R, Walford RL (1982) Dietary restriction in mice beginning at 1 year of age: effect on life-span and spontaneous cancer incidence. Science 215:1415-1418

Wilson EO (1971) The insect societies. Belknap Press, Cambridge

Yu C, Li Y, Holmes A et al (2011) RNA sequencing reveals differential expression of mitochondrial and oxidation reduction genes in the long-lived naked mole-rat when compared to mice. PLoS One 6:e26729. doi:10.1371/journal.pone.0026729

Zerbino DR, Birney E (2008) Velvet: algorithms for de novo short read assembly using de Bruijn graphs. Genome Res 18:821-829. doi:10.1101/gr.074492.107

Zhang X, Goodsell J, Norgren RB (2012) Limitations of the rhesus macaque draft genome assembly and annotation. BMC Genom 13:206. doi:10.1186/1471-2164-13-206

Zhao M, Lee W-P, Garrison EP, Marth GT (2013) SSW library: an SIMD Smith-Waterman $\mathrm{C} / \mathrm{C}++$ library for use in genomic applications. PLoS One 8:e82138. doi:10.1371/journal.pone. 0082138

Zhao S, Lin L, Kan G et al (2014) High autophagy in the naked mole rat may play a significant role in maintaining good health. Cell Physiol Biochem 33:321-332. doi:10.1159/000356672

Zimin AV, Kelley DR, Roberts M et al (2012) Mis-assembled "segmental duplications" in two versions of the Bos taurus genome. PLoS One 7:e42680. doi:10.1371/journal.pone.0042680

Ziv E, Hu D (2011) Genetic variation in insulin/IGF-1 signaling pathways and longevity. Ageing Res Rev 10:201-204. doi:10. 1016/j.arr.2010.09.002 